\title{
Mass analysis of charged aerosol particles in NLC and PMSE during the ECOMA/MASS campaign
}

\author{
S. Robertson ${ }^{1}$, M. Horányi ${ }^{1}$, S. Knappmiller ${ }^{1}$, Z. Sternovsky ${ }^{1}$, R. Holzworth ${ }^{2}$, M. Shimogawa ${ }^{2}$, M. Friedrich ${ }^{3}$,

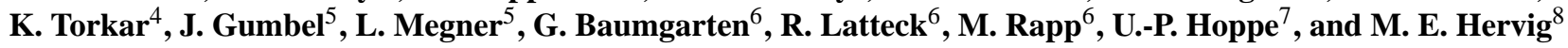 \\ ${ }^{1}$ Laboratory for Atmospheric and Space Physics, University of Colorado, Boulder, CO 80309, USA \\ ${ }^{2}$ Earth and Space Sciences, University of Washington, Seattle, WA 98195 USA \\ ${ }^{3}$ Institute of Communication Networks and Satellite Communications, Graz University of Technology, 8010 Graz, Austria \\ ${ }^{4}$ Space Research Institute, Austrian Academy of Sciences, 8042 Graz, Austria \\ ${ }^{5}$ Department of Meteorology, Stockholm University, 10691 Stockholm, Sweden \\ ${ }^{6}$ Leibniz Institute for Atmospheric Physics, 18225 Kühlungsborn, Germany \\ ${ }^{7}$ Norwegian Defence Research Establishment (FFI), 2027 Kjeller, Norway \\ ${ }^{8}$ GATS, Inc., Driggs, Idaho, 83422, USA
}

Received: 20 October 2008 - Revised: 21 January 2009 - Accepted: 4 February 2009 - Published: 12 March 2009

\begin{abstract}
MASS (Mesospheric Aerosol Sampling Spectrometer) is a multichannel mass spectrometer for charged aerosol particles, which was flown from the Andøya Rocket Range, Norway, through NLC and PMSE on 3 August 2007 and through PMSE on 6 August 2007. The eight-channel analyzers provided for the first time simultaneous measurements of the charge density residing on aerosol particles in four mass ranges, corresponding to ice particles with radii $<0.5 \mathrm{~nm}$ (including ions), $0.5-1 \mathrm{~nm}, 1-2 \mathrm{~nm}$, and $>3 \mathrm{~nm}$ (approximately). Positive and negative particles were recorded on separate channels. Faraday rotation measurements provided electron density and a means of checking charge density measurements made by the spectrometer. Additional complementary measurements were made by rocket-borne dust impact detectors, electric field booms, a photometer and ground-based radar and lidar. The MASS data from the first flight showed negative charge number densities of 1500 $3000 \mathrm{~cm}^{-3}$ for particles with radii $>3 \mathrm{~nm}$ from $83-88 \mathrm{~km}$ approximately coincident with PMSE observed by the ALWIN radar and NLC observed by the ALOMAR lidar. For particles in the $1-2 \mathrm{~nm}$ range, number densities of positive and negative charge were similar in magnitude $\left(\sim 2000 \mathrm{~cm}^{-3}\right)$ and for smaller particles, $0.5-1 \mathrm{~nm}$ in radius, positive charge was dominant. The occurrence of positive charge on the aerosol particles of the smallest size and predominately negative charge on the particles of largest size suggests that nucle-
\end{abstract}

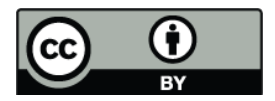

Correspondence to: S. Knappmiller (knappmil@colorado.edu) ation occurs on positive condensation nuclei and is followed by collection of negative charge during subsequent growth to larger size. Faraday rotation measurements show a bite-out in electron density that increases the time for positive aerosol particles to be neutralized and charged negatively. The larger particles $(>3 \mathrm{~nm})$ are observed throughout the NLC region, $83-88 \mathrm{~km}$, and the smaller particles are observed primarily at the high end of the range, $86-88 \mathrm{~km}$. The second flight into PMSE alone at $84-88 \mathrm{~km}$, found only small number densities $\left(\sim 500 \mathrm{~cm}^{-3}\right)$ of particles $>3 \mathrm{~nm}$ in a narrow altitude range, $86.5-87.5 \mathrm{~km}$. Both positive $\left(\sim 2000 \mathrm{~cm}^{-3}\right)$ and negative $\left(\sim 4500 \mathrm{~cm}^{-3}\right)$ particles with radii $1-2 \mathrm{~nm}$ were detected from $85-87.5 \mathrm{~km}$.

Keywords. Atmospheric composition and structure (Aerosols and particles; Cloud physics and chemistry) Ionosphere (Polar ionosphere)

\section{Introduction}

The noctilucent clouds (NLC) that appear in the polar summer mesosphere result from the growth of ice on condensation nuclei that may be meteoritic dust particles or ions (Turco et al., 1982; Hunten et al., 1980; Witt, 1969). The aerosol particles reside in the D-region of the ionosphere and thus create dusty plasma (Goertz, 1989) of electrons, ions, and charged aerosol particles. Attachment of electrons to these aerosol particles reduces the electron mobility and allows the persistence of modulations in the electron

Published by Copernicus Publications on behalf of the European Geosciences Union. 
density arising from atmospheric turbulence. Modulation at the Bragg scale results in enhanced radar backscatter called Polar Mesosphere Summer Echoes (PMSE). These radar observations can arise from particles smaller than those responsible for NLC. PMSE show that icy aerosol particles occur more frequently than NLC and over a wider range of altitudes (Rapp and Lübken, 2004). The particles may capture sufficient numbers of electrons to cause reductions in electron density called "bite-outs" that were observed by rocket-borne plasma probes and in Faraday rotation data (Pedersen et al., 1970; Ulwick et al., 1988; Croskey et al., 2004). Ion mass spectrometers have also measured reductions in ion density when NLC are present (Balsiger et al., 1996).

The ice particles that grow to become NLC are sufficiently large to be seen by optical scattering methods: lidars (von Cossart et al., 1999), satellite-borne cameras (DeLand et al., 2006; Russell et al., 2008), and rocket-borne photometers (Gumbel et al., 2001). Ice particles have recently been detected by optical extinction using a satellite-borne limb scanner (Gordley et al., 2008; Hervig et al., 2009). Analysis of scattering data of visible NLCs typically finds the characteristic sizes in the range $20-100 \mathrm{~nm}$ with number densities of order $100 \mathrm{~cm}^{-3}$ (e.g. Baumgarten et al., 2008). Much less is known about the subvisual aerosol particles, although these have a significantly larger number density. The detection of these particles by rocket-borne instruments is made possible through the collection of the charge they carry. If the number density of aerosol particles is much less than the plasma density, the attachment of electrons to aerosol particles occurs at a much higher rate than the attachment of ions, thus the number density of aerosol particles with negative charge greatly exceed the number density with positive charge (Rapp and Lübken, 2001). If the number density of aerosol particles is sufficient to deplete the electron density, then the relative probability of collecting ions is increased.

Unicharged ice particles have been detected by particle impact detectors (Zadorozhny et al., 1997). Havnes et al. (1996) flew a Faraday cup through NLC and found negative particles but also positive particles in number densities too large to be accounted for by the standard plasma charging model. Positive particles have also been observed by detectors of different designs (Blix et al., 2003; Smiley et al., 2003) and in the absence of NLC conditions (Gelinas et al., 1998; Rapp et al., 2005; Amyx et al., 2008). The possibility of photoelectric charging has been considered (Havnes et al., 1990; Rapp and Lübken, 1999), but this would require a reduction of the work function of ice by easily-ionized impurities such as sodium. Recent experiments show that this reduction occurs in the laboratory but the usual concentration of $\mathrm{Na}$ is too small to account for observations in the mesosphere (Vondrak et al., 2006a, b). In a single-channel instrument that collects the net charge of aerosol particles the detection of a large number of negative particles (for example) can mask the detection of positive particles.
The aerodynamic flow around a rocket payload may carry the smallest particles around the detector (Rapp et al., 2005; Hedin et al., 2007; Amyx et al., 2008). An alternate detector design, the Gerdien condenser, is open at the bottom and allows passage of air through the instrument. There is an upper bound on mass that can be varied by scanning the collector voltage (Croskey et al., 2001), but the scanning results in a loss of altitude resolution. The number density of the charged fraction of the aerosol particles has been deduced from the data of these charge-collecting instruments and is of order $10^{3} \mathrm{~cm}^{-3}$, which is much greater than the number densities of visible NLC particles. Recently, the uncharged aerosol particles (including meteoritic particles) have been detected by instruments on a payload carrying a flashlamp for active photoioinization (Rapp and Strelnikova, 2008).

We present data from two flights of rocket-borne multichannel mass analyzers for charged aerosol particles that were flown into PMSE and NLC on 3 August 2007 (MASS1) and into PMSE alone on 6 August 2007 (MASS2). The flights were part of the ECOMA/MASS campaign that combined three rocket flights, ground-based measurements by lidar and radar, and observations by the AIM (Aeronomy of Ice in the Mesosphere) satellite (Russell et al., 2008). The two MASS payloads carried the Mesospheric Aerosol Sampling Spectrometer (MASS), which is a multichannel mass analyzer that simultaneously collects both the positive and negative charge residing on aerosol particles (Knappmiller et al., 2008). The spectrometer has four pairs of collecting surfaces contained within the instrument housing for four ranges of particle size. The analyzer uses electrostatic deflection so that particles of different sizes are collected on different pairs of plates, with one of the pair collecting positive particles and the other collecting negative particles. Air passes through the instrument continuously, thus aerodynamics has only a small mass-selective effect.

The rocket payloads and the principles of operation of the MASS instruments are discussed in Sect. 2. Flight data from the upleg and downleg of MASS1 and of MASS2 are presented in Sects. 3 and 4, respectively. The data show that within the NLC/PMSE region at $83-88 \mathrm{~km}$ on $3 \mathrm{Au}-$ gust 2007, particles with radii $>3 \mathrm{~nm}$ were predominately negative with charge number densities up to $3000 \mathrm{~cm}^{-3}$. In the narrower altitude range $86-88 \mathrm{~km}$, there were both positive and negative aerosol particles with radii $1-2 \mathrm{~nm}$ with comparable number densities near $2000 \mathrm{~cm}^{-3}$, and the particles with radii $0.5-1 \mathrm{~nm}$ were positive with number densities near $2000 \mathrm{~cm}^{-3}$. Particles with radii $>3 \mathrm{~nm}$ were nearly absent in the 6 August flight into PMSE alone. These data are discussed in more detail in Sect. 5 where it is argued that the occurrence of positive particles at the smallest sizes is more consistent with the growth of ice on positively charged condensation nuclei than with either photoelectric charging or the capture of positive ions by neutral aerosol particles. The condensation nuclei being ions rather than meteoric dust is also supported by recent circulation models that show 
number densities of sufficiently-large meteoric particles that are too low to account for the number densities of charged aerosol particles (Megner et al., 2006, 2008; Bardeen et al., 2008). Section 6 is a short summary and conclusion.

\section{The MASS payloads}

The two MASS payloads, Fig. 1, were practically identical. Each had four instruments: a MASS analyzer, fore and aft electric field booms (e.g. Holzworth and Goldberg, 2004), a photometer (Gumbel and Witt, 2001), and an antenna pair for Faraday rotation measurements of electron density (Jacobsen and Friedrich, 1979). The attitude control system (ACS) and telemetry were located between the fore and aft experimental sections. The ACS was programmed to adjust the spin rate to $2 \mathrm{~Hz}$ (above $80 \mathrm{~km}$ ) and to keep the rocket pointed in the ram direction from $75-95 \mathrm{~km}$ on the upleg and downleg so that aerosol particles entered the MASS analyzer with velocity vectors parallel to the instrument axis. Post-flight analysis of data indicated that the pointing error was less than 1 degree. The telemetry operated with an amplitude resolution of 12 bits and at a $1.1 \mathrm{kHz}$ sampling rate corresponding to an altitude resolution of approximately $0.9 \mathrm{~m}$. The MASS analyzer data were smoothed to reduce high frequency noise using a Gaussian window function having a width of $10 \mathrm{~ms}$.

The MASS instrument (Knappmiller et al., 2008) is an electrostatic mass analyzer for nanometer-sized charged aerosol particles that is mounted at the top of the rocket payload. The instrument uses the electrostatic force to deflect the charged particles so that their charge is deposited on a set of collection plates with bias voltages. On one side of the analyzer are three negatively-biased graphite plates for collection of positive particles and on the opposite side there are three positively-biased plates for negative particles (Fig. 2a). The bias voltages on the first three pairs of plates are $\pm 1.7 \mathrm{~V}$, $\pm 5.4 \mathrm{~V}$ and $\pm 54 \mathrm{~V}$. An additional pair of unbiased plates collects the largest particles with small deflection. Deflecting these particles would require voltages sufficiently large for a risk of electrical breakdown. The positive and negative aerosol particles are thus sorted into mass bins with radii in the ranges $<0.5 \mathrm{~nm}, 0.5-1 \mathrm{~nm}, 1-2 \mathrm{~nm}$, and $>3 \mathrm{~nm}$ (approximately). The radius is found from the mass by assuming that the particles are spherical and have the density of water ice $\left(931 \mathrm{~kg} / \mathrm{m}^{3}\right)$.

The collection efficiency as a function of mass for each of the collection plates, Fig. 2a, is found for atmospheric conditions at $2.5 \mathrm{~km}$ intervals from 80 to $90 \mathrm{~km}$ using a detailed three-dimensional numerical simulation, which calculates the trajectories of the charged aerosol particles. The temperatures and densities are taken from Lübken (1999). The collection efficiencies from the simulations are summarized in Table 1 for the altitudes of 80 and $90 \mathrm{~km}$ that bracket the PMSE region. Collection efficiency curves for $87.5 \mathrm{~km}$ (near to the location of the highest density of nanometer-

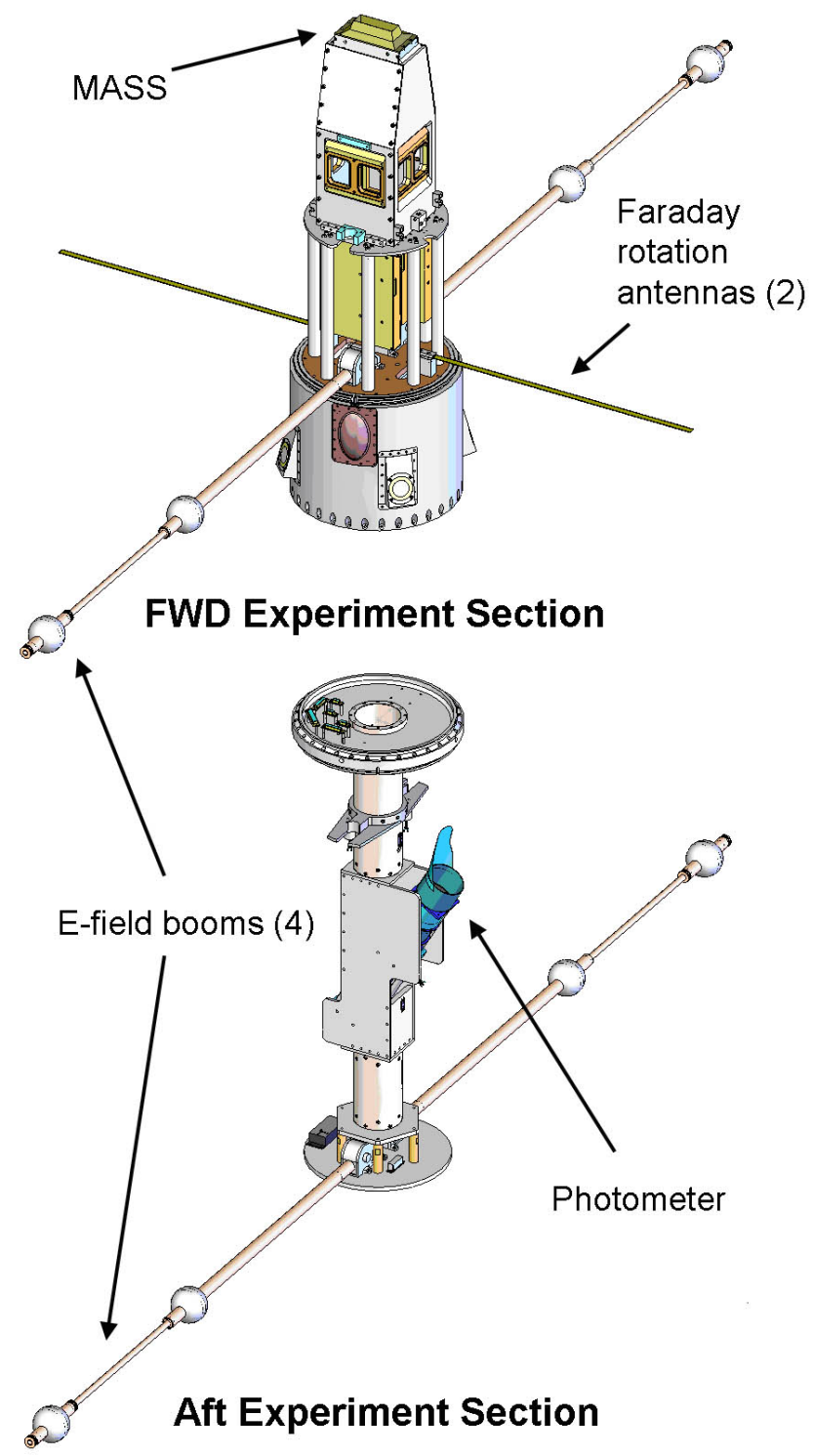

Fig. 1. Engineering drawing of the MASS payloads consisting of the forward (FWD) experimental section and the aft experimental section. The diameter of the rocket skin is $36 \mathrm{~cm}$. The electric field booms span $3 \mathrm{~m}$ tip-to-tip when fully deployed and their vertical separation is also $3 \mathrm{~m}$.

sized particles) are shown in Fig. 2b. The collection efficiency for a given mass is defined as the number of particles collected by a plate divided by the number of particles started directly upstream of the slit opening. The simulations required three numerical models. The first solves Laplaces's equation in three dimensions inside of the instrument housing to determine the electrostatic potential profile. The second finds the aerodynamic flow in three dimensions around and within the instrument by the direct simulation Monte-Carlo method (Bird, 1994; Gumbel, 2001; Hedin et al., 2007). The third finds the trajectories of the charged 

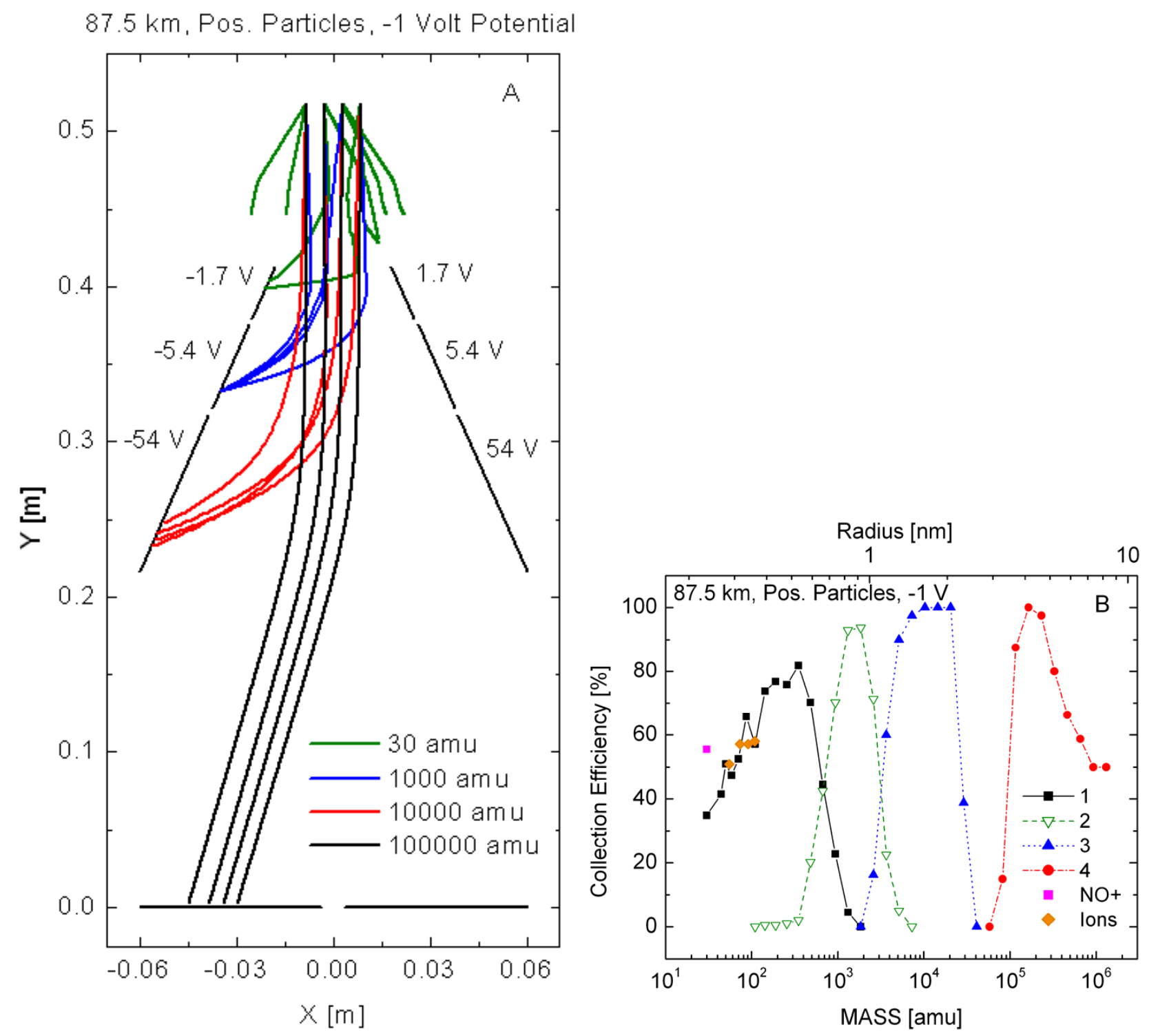

Fig. 2. (A) Plots of simulated trajectories of charged ice particles within the MASS instrument. At least 4 trajectories are plotted for each of the 4 particle masses. The trajectories are terminated if they hit an interior surface or if they leave the sampled air volume before entering the instrument. The assumed payload potential is $-1 \mathrm{~V}$. (B) Sensitivity curves from the numerical simulations that show the relative sensitivity of each channel as a function of mass at $87.5 \mathrm{~km}$. Particles with radii 2-3 nm are deflected toward the air exit windows and thus do not fall on a collector plate, leaving a gap near $25000 \mathrm{amu}$ in the collected range of mass. The filled diamond symbols labeled "Ions" is for the proton hydrates with masses $55,73,91$, and 109 amu and the magenta square is for the $\mathrm{NO}^{+}$ion.

aerosol particles from the equations of motion using (1) the force of the electrostatic field assuming unit charge on the aerosol particle and (2) the impulsive changes to the particles' velocity vector caused by random collisions with air molecules. The number density, temperature, and flow velocity of the air and the electric field are used as inputs to the trajectory modeling code. Trajectories are found for 35 logarithmically-spaced masses from 30 to $1.3 \times 10^{6} \mathrm{amu}$. The trajectories are started $82 \mathrm{~mm}$ above the opening in an area sufficiently larger than the slit to allow scattering both into and out of the sampled volume of air. Additional (preflight) sensitivity curves for vacuum conditions were obtained experimentally using an ion source. Details of the flow simulations and particle trajectory calculations are given in Knappmiller et al. (2008).

In the trajectory simulations, the collision cross sections of the aerosol particles are calculated from an effective radius that is the radius of a sphere of ice plus an effective 
Table 1. Ranges of masses detected by each of the eight MASS channels calculated for atmospheric conditions at $80 \mathrm{~km}$ and $90 \mathrm{~km}$. Columns 2 and 3 are with no assumed rocket potential. Columns 3 and 4 are with an assumed potential of $-1 \mathrm{~V}$ (Knappmiller et al., 2008). The range listed is the range for which the collection efficiency for the channel exceeds half the maximum for that channel.

\begin{tabular}{cllll}
\hline $\begin{array}{l}\text { Channel } \\
\text { number }\end{array}$ & $\begin{array}{l}80 \mathrm{~km} \\
{[\mathrm{amu}]}\end{array}$ & $\begin{array}{l}90 \mathrm{~km} \\
{[\mathrm{amu}]}\end{array}$ & $\begin{array}{l}80 \mathrm{~km}-1 \mathrm{~V} \\
{[\mathrm{amu}]}\end{array}$ & $\begin{array}{l}90 \mathrm{~km}-1 \mathrm{~V} \\
{[\mathrm{amu}]}\end{array}$ \\
\hline $1+$ & $<200$ & $70-800$ & $<300$ & $35-600$ \\
$1-$ & $<200$ & $70-800$ & $<250$ & $200-900$ \\
$2+$ & $200-1500$ & $800-3000$ & $180-1500$ & $600-3000$ \\
$2-$ & $200-1500$ & $800-3000$ & $160-1500$ & $900-3000$ \\
$3+$ & $1500-30000$ & $3000-25000$ & $1500-30000$ & $3000-25000$ \\
$3-$ & $1500-30000$ & $3000-25000$ & $1600-22000$ & $3000-28000$ \\
$4+$ & $>50000$ & $>85000$ & $>95000$ & $>80000$ \\
$4-$ & $>50000$ & $>85000$ & $>90000$ & $>90000$ \\
\hline
\end{tabular}

radius of a nitrogen molecule (Dushman, 1962) because nitrogen is the dominant neutral species. The cross section being that for a solid sphere is poor for particles below a few hundred amu in mass where collisions are better described by quantum mechanics than by classical mechanics. For the mass $30 \mathrm{amu}$ corresponding to $\mathrm{NO}^{+}$ions, additional simulations were done using measured cross sections for collisions of $\mathrm{NO}^{+}$with $\mathrm{N}_{2}$ molecules (Viehland and Mason, 1995). This cross section is velocity dependent and the value used $\left(2.1 \times 10^{-15} \mathrm{~cm}^{2}\right)$ is for a typical relative velocity for the collisions in the simulations. For masses 55, 73, 91, and $109 \mathrm{amu}$, corresponding to the proton hydrates $\mathrm{H}^{+}\left[\mathrm{H}_{2} \mathrm{O}\right]_{n}$ with $n=3,4,5$, and 6 , simulations were done with cross sections from Sternovsky et al. (2001). The collection efficiencies could easily be in error by $20 \%$ because of uncertainties in cross sections. The error is greater if the particles are fluffy aggregates that have an effective collision cross section different from that indicated by their mass.

The nominal mass range collected by each plate is affected in flight by the payload charging potential and by the collision frequency of the aerosol particles with air molecules, which changes with altitude. The effect of a higher collision frequency is to widen the range of masses collected by each plate as particles are scattered into and out of the flow field. The effect of collisions is largest for the smallest masses at lower altitudes where the atmospheric density is the largest (Knappmiller et al., 2008). Measurements of the charging potentials of rockets in the mesosphere indicate values of approximately -1 volt (Friedrich et al., 1997). The payload did not carry a Langmuir probe biased for electron density measurement because electron collection by a probe often results in the payload being several volts negative (e.g. Strelnikova et al., 2009). The expected payload potential is nonnegligible in comparison with the bias potentials on the first two pairs of collection plates. Simulations were done with and without -1 volt on the payload for both positive and neg-
Table 2. Kinetic energy as a function of radius and mass for aerosol particles of ice. A velocity of $1 \mathrm{~km} / \mathrm{s}$ is assumed.

\begin{tabular}{ccc}
\hline Radius [nm] & Mass [amu] & Kinetic energy [eV] \\
\hline 0.5 & 288 & 1.7 \\
1.0 & 2310 & 13.6 \\
2 & 18500 & 108 \\
3 & 62300 & 366 \\
5 & 288000 & 1700 \\
\hline
\end{tabular}

ative aerosol particles to evaluate its effect on the sensitivity curves. The payload potential effect is found to be dependent upon the collision frequency. At $80 \mathrm{~km}$ a payload potential of $-1 \mathrm{~V}$ has negligible effect on particles with either sign of charge because the incoming particles are prevented by collisions from being significantly accelerated by the change in potential above the entrance slit. However, at $90 \mathrm{~km}$ the payload potential retards negatively charged aerosols limiting the collection of particles below $\sim 200$ amu and it accelerates the positive aerosols enhancing their collection between 200 and $900 \mathrm{amu}$. The range of masses collected by each MASS channel are listed in Table 1 with and without a rocket potential of $-1 \mathrm{~V}$. The primary source of uncertainty in the range of masses collected is from the uncertainty in the payload potential. Table 2 shows the energies in electron volts with which aerosol particles enter the instrument as a function of radius and mass. The effect of a $-1 \mathrm{~V}$ rocket potential on a singly charged particle is small for an incident particle energy of $\sim 7 \mathrm{eV}$ or more which applies to particles with radii greater than $\sim 0.75 \mathrm{~nm}$ ( $\sim 900 \mathrm{amu})$. Simulations for electrons were not done, however, it can be inferred from the trajectories of the lightest negative particles that (1) electron collection is prevented by a potential of $-1 \mathrm{~V}$ in the absence of collisions and (2) that without the charging potential the high thermal velocity of electrons would carry a large fraction into the walls of the entrance slit.

The current flowing to a collection plate is of the order of $1 \mathrm{nA}$ and is measured by an electrometer. The collected current $I$ is related to the number density of charge by $I=f n q v A$ where $f$ is the collection efficiency, $n$ is the charge number density, $v$ is the rocket velocity, and $A=25.2 \mathrm{~cm}^{2}$ is the slit area. The number density of aerosol particles is found from the current $I$ assuming a single charge on the aerosol particle, using an interpolated value of the rocket velocity $v$ as a function of altitude, and using the peak value of $f$ at $87.5 \mathrm{~km}$ for the channel being analyzed at $-1 \mathrm{~V}$ rocket potential (Fig. 2b). The collection efficiency for the top most plate, which collects the smallest particles, is very sensitive to collisions with the background air density. The uncertainty in the collection efficiency for the smallest particles is correlated to the uncertainty in the cross section. Therefore, the collection efficiency for the top plate is determined by using 
the cross section of the dominate ion species $\mathrm{NO}^{+}$at $90 \mathrm{~km}$ where the air density is lower. At a typical rocket speed of $1 \mathrm{~km} / \mathrm{s}$, a current of $1 \mathrm{nA}$ corresponds to a charge number density of $2340 \mathrm{~cm}^{-3}$ for $f=1.0$.

The data quality may be affected by the occurrence of spurious currents from two sources. The first is photoemission from the collecting surfaces caused by solar ultraviolet radiation. This effect is minimized by having the collection surfaces within an enclosure and by having graphite collection surfaces which have a low photoelectron yield (Feuerbacher and Fitton, 1972). The second effect is the generation of charged fragments created by the impact of ice particles that has been observed in laboratory experiments (Vostrikov et al., 1987, 1988, 1997; Andersson and Pettersson, 1997) and proposed as an explanation for some signals from rocketborne instruments (Havnes and Næsheim, 2007). Charge generation is largest for the aerosol particles with the greatest mass. The upper collecting surfaces within the MASS instrument slope away from the slit opening so that the particles incident on each plate are only the charged particles in the desired mass range. Spurious charge generation would be most likely for the fourth pair of plates at the bottom of the instrument that receive the heaviest charged aerosol particles and the undeflected neutral particles. Below, in Sect. 3.5 it is argued that these spurious currents are absent.

\section{MASS1 flight data}

Data from the MASS instrument were obtained on the upleg and downleg of each flight. The data for MASS1 are presented in this section and the data for MASS2 are presented in Sect. 4. Within each section, the conditions at launch are described and then the data for upleg and downleg are presented in order of increasing mass. The lowest-mass channels collecting positive and negative charge are labeled 1+ and $1-$, respectively, and the highest mass channels are 4+ and $4-$. Three checks are made on the data quality. First, in Sect. 3.2, the positive ion density from the channel 1+ (positive ions) is compared to the electron density in regions where they are expected to be nearly equal. Second, signals are examined in Sect. 3.5 to find if there is evidence for the creation of charge by impacts of neutral particles. Third, in Sect. 5.1 the sum of the positive and negative charge densities is examined to determine if the sum is consistent with quasineutrality.

\subsection{Launch conditions for MASS1}

The launches were made from the Andøya Rocket Range $\left(69^{\circ} \mathrm{N}, 16^{\circ} \mathrm{E}\right)$, Norway, which is collocated with the ALOMAR observatory. Launch decisions were aided by groundbased data from the ALWIN radar (Latteck et al., 1999) and the ALOMAR RMR lidar (von Zahn et al., 2000). A launch window in the first two weeks of August was selected to be both within the NLC season and to have a low solar elevation angle near local midnight to minimize solar ultraviolet radiation that may affect instruments. It was also desired to maximize scientific return by having launches as near in time as possible to the ECOMA3 rocket launch (Rapp et al., 2009) and having in situ measurements during the operating period of the AIM satellite launched in April 2007.

MASS1 (NASA designation 41.069) was launched on 3 August 2007 and reached an apogee of $133.3 \mathrm{~km}$. Preparations for launch were started at 17:00 UTC during a strong PMSE observed with the ALWIN radar and were suspended for several hours when the PMSE became weak. The countdown was resumed when the PMSE strengthened, Fig. 3, and the launch occurred at 22:51:20 UTC. The solar zenith angle was 93.2 degrees. The rocket velocity dropped from $1106 \mathrm{~m} / \mathrm{s}$ at $80 \mathrm{~km}$ to $1018 \mathrm{~m} / \mathrm{s}$ at $90 \mathrm{~km}$. The PMSE showed a double structure with peaks at 83 and $88 \mathrm{~km}$, which is common (Hoffmann et al., 2005). Approximately 5 min before the launch the ALOMAR RMR lidar, Fig. 4, showed a weak NLC at $82-84 \mathrm{~km}$ with a peak backscatter coefficient of only $3.3 \times 10^{-10}(\mathrm{~m} \mathrm{sr})^{-1}$ at $82.8 \mathrm{~km}$. At the launch time, lidar measurements were not possible due to tropospheric clouds. Further details of the ground-based measurements are reported in Baumgarten et al. (2009).

\subsection{Channels 1+ and 1-, ion and electron densities}

The Faraday rotation measurement, Fig. 5, provides electron density as well as a means of checking charge densities measured by the MASS instrument. The Faraday rotation data show a bite-out in electron density in the altitude range 78$90 \mathrm{~km}$ that is closely coincident with the PMSE indicating that the electrons have been scavenged by the aerosol particles. The upper limit of the electron density bite-out closely agrees with that of the reflected power measured by the ALWIN radar, the bite-out signature at the lower boundary of the radar echo at $81 \mathrm{~km}$ is less pronounced. This is primarily because of the uncertainty of the wave propagation electron densities at that height due to the large collision frequency (Friedrich et al., 2009). But also the normalization factor to convert the ion current to ion density is an extrapolation from higher altitudes and makes ion densities somewhat uncertain at $80 \mathrm{~km}$. The electron densities during both MASS flights are about average considering solar zenith angle, season and concurrent riometer absorption. The large electron density bite-out occurs in about 20\% of PMSE events (Blix et al., 2003).

Electron densities are not obtained from MASS because electron collection is suppressed by the negative payload potential and the high thermal velocities of the electrons cause a large fraction to strike the walls of the entrance slit. The quasineutrality condition requires that the positive and negative charge densities be equal in magnitude, thus the positive charge density should equal the negative charge density. In regions where there are no charged aerosol particles and no 



Fig. 3. Upper panel: ALWIN radar data for the 15 min period nearest the launch of MASS1. Lower panel: ALWIN radar data for the 15 min period nearest the launch of MASS2.

negative ions, the positive ion density obtained from channel 1+ of the MASS instrument should be equal to the electron density from Faraday rotation. The data from channel $1+$ for the lightest positive particles are plotted together with the electron density for $74-100 \mathrm{~km}$ in Fig. 5a. The densities are nearly equal from $90-100 \mathrm{~km}$. The positive charge density is found using the collection efficiency of $f=0.64$ taken from the calculations made for $\mathrm{NO}^{+}$at $90 \mathrm{~km}$. The $\mathrm{NO}^{+}$ion has been found to be the most abundant ion in this altitude range by rocket-borne mass spectrometers (e.g. Bragin and
Shamakhov, 1982; Krankowsky et al., 1987). Negative ions are negligible at these altitudes (e.g. Thomas and Bowman, 1985).

The data from channels $1+$ and $1-$ are plotted for the PMSE region, $80-90 \mathrm{~km}$, for the MASS1 upleg in Fig. 6. Inspection of data from all the MASS channels shown in Fig. 6 shows that the largest signals are from channel $1+$ for the lightest positive particles and channels 4 for the heaviest particles. The heaviest particles are collected throughout the PMSE layer from $83-88 \mathrm{~km}$. The lightest particles (including 


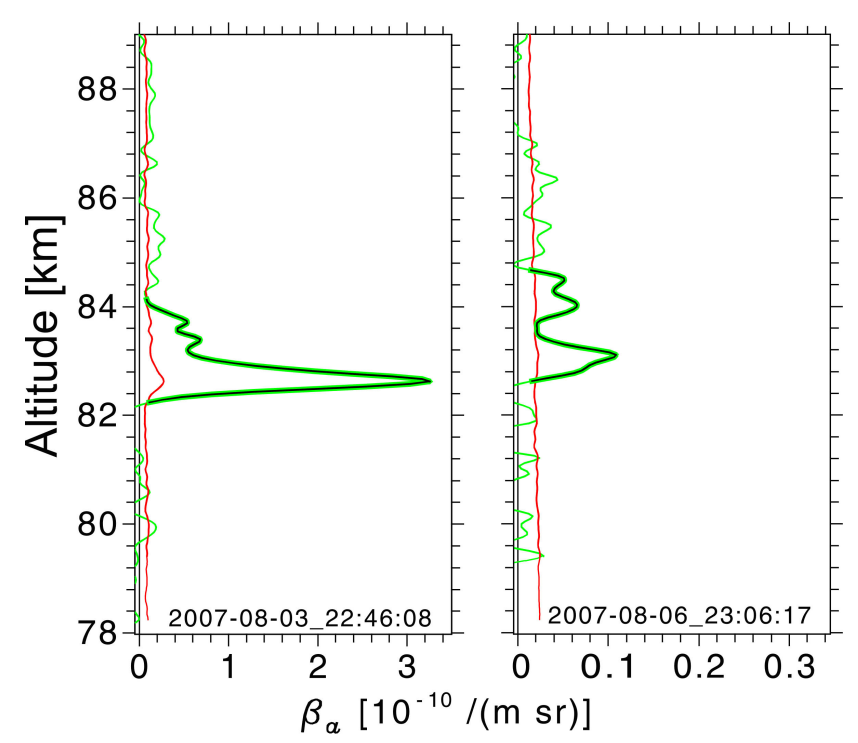

Fig. 4. Aerosol backscatter coefficients (green) measured by the ALOMAR RMR-Lidar during MASS1 (left panel) and MASS2 (right) panel from the lidar system looking close to the rocket trajectory. During MASS1 the integration time was reduced to $1 \mathrm{~min}$, while during MASS2 14 min integration time was used to detect the weak NLC (note the different scaling on the abscissa). The red lines indicate the 1-sigma measurement uncertainty.

ions) are most affected by the rocket charging potential. The signal from channel $1-$ is small, indicating negative charge densities below $\sim 1000 \mathrm{~cm}^{-3}$. Electron collection is clearly suppressed because there is negligible negative charge collection $\left(\leq 500 \mathrm{~cm}^{-3}\right)$ in the region $88-90 \mathrm{~km}$ where Faraday rotation indicates electron densities approaching $5000 \mathrm{~cm}^{-3}$. Channel $1+$ collecting positive charge increases smoothly with altitude below $83 \mathrm{~km}$ and above $88 \mathrm{~km}$. The region $83-$ $86 \mathrm{~km}$ shows a local enhancement and $86-88 \mathrm{~km}$ shows a local deficit relative to the smooth increase. The deficit at $86-88 \mathrm{~km}$ overlaps with an enhancement in positive charge density on the channels $2+$ and $3+$ for larger mass (note the different vertical scales) and together these data indicate a shift of the positive charge onto particles of greater mass at $86-88 \mathrm{~km}$.

The downleg data for MASS1 are plotted in Fig. 7. Signals identical to those on the upleg are not expected because the sampled volume at PMSE altitude is displaced horizontally by about $90 \mathrm{~km}$ from the volume sampled on the upleg and the PMSE was highly variable. Inspection of all MASS channels shows that the heaviest particles, channels 4 , are seen in a more limited range $(87-89 \mathrm{~km})$ than on the upleg. For channel $1+$ collecting positive charge, there is a smooth increase to a density of about $1.2 \times 10^{4} \mathrm{~cm}^{-3}$ which is comparable to the density recorded on the upleg. The signal shows a reduction in density at $85-86 \mathrm{~km}$ that is similar to the reduction at $86-88 \mathrm{~km}$ seen on the upleg. Channel $1-$ shows only $200 \mathrm{~cm}^{-3}$, indicating that negative ions in the range 200 $900 \mathrm{amu}$ (approximately) are nearly absent.
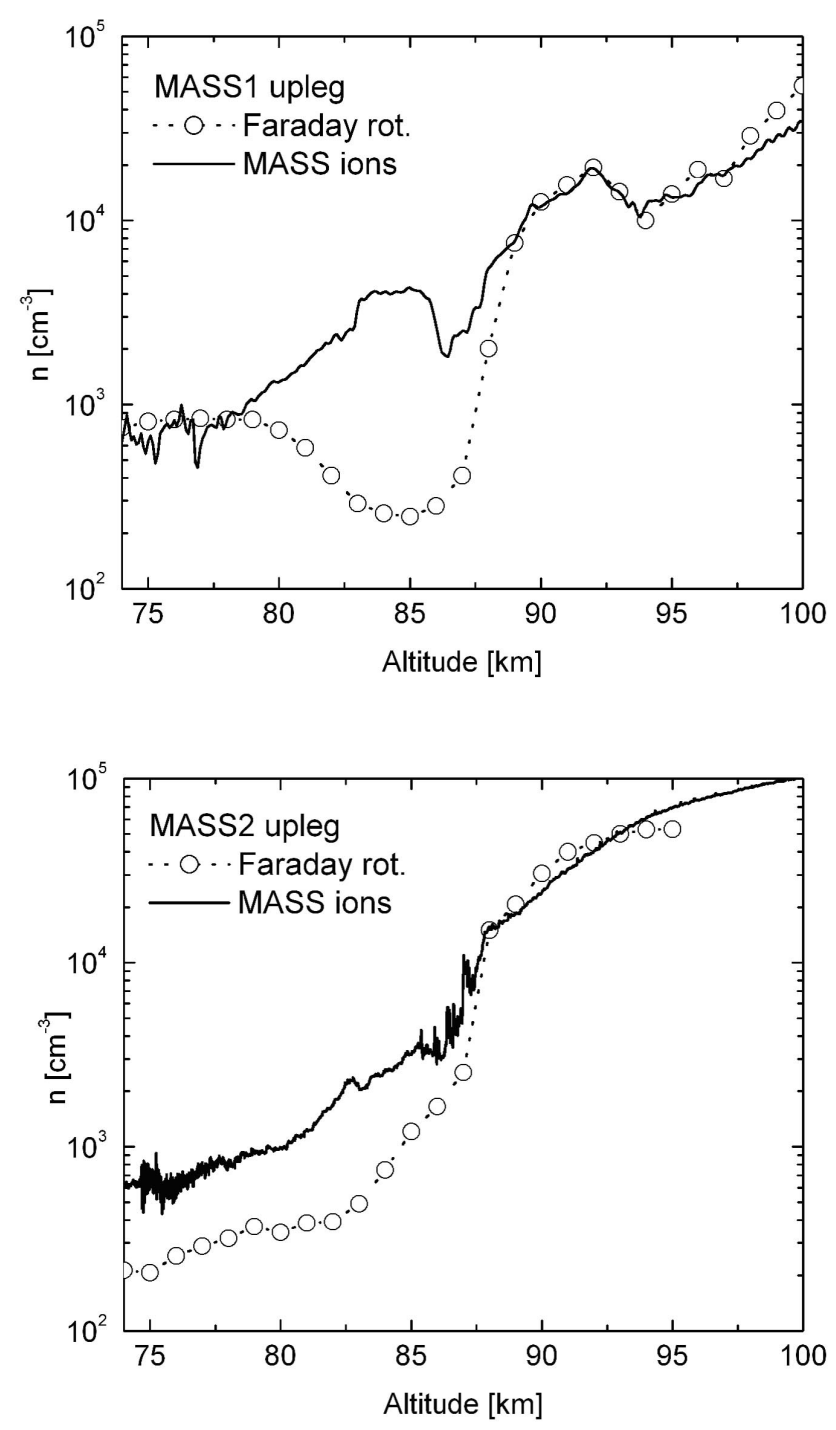

Fig. 5. The electron density from Faraday rotation for MASS1 (upper panel) and MASS2 (lower panel) are plotted with the positive ion density indicated by MASS analyzer channel $1+$ for the lightest positive particles. In the data analysis for the MASS channel, a collection efficiency of 0.64 is used from the simulations with $-1 \mathrm{~V}$ payload potential for $\mathrm{NO}+$ at $90 \mathrm{~km}$.

\subsection{Channels 2+ and 2- $(0.5-1.0 \mathrm{~nm}$, nominally $)$}

Channel $2+$ collects positive particles in a well-defined layer from $86-88 \mathrm{~km}$ on the upleg with a number density of 1000 $2000 \mathrm{~cm}^{-3}$, Fig. 6. As discussed above, at the same range of altitudes there is a deficit in the positive charge density recorded on channel 1+. This is the usual location of the temperature minimum for the arctic summer (Lübken, 1999) and the observation suggests that the particles originate in this range of altitudes. However, the data from the ECOMA3 rocket flight (about $30 \mathrm{~min}$ after MASS1) indicate a lower altitude of $\sim 85 \mathrm{~km}$ for the temperature minimum. There is no 



Fig. 6. Data from the 8 channels of the MASS instrument for the upleg of the first flight. Channels 4+ and 4- are offset from zero for clarity and their sum is plotted correctly.

indication on channel 2- of a corresponding layer of negative aerosol particles. However, there may be light negative ions (less than $200 \mathrm{amu}$, depending on altitude) that are not collected because of the payload charging potential.

On the downleg of MASS1, Fig. 7, channel 2+ shows a positive charge layer at $85-86 \mathrm{~km}$ with a peak density of about $1200 \mathrm{~cm}^{-3}$. Particles of this size were seen at $86-$ $88 \mathrm{~km}$ on the upleg. As on the upleg, channel 2- shows no structure indicating a negative charge layer.

\subsection{Channels 3+ and 3- (1-2 nm, nominally)}

Channels $3+$ and 3- both indicate a charge layer spanning $86-88 \mathrm{~km}$ on the upleg. The charge density is about $2000 \mathrm{~cm}^{-3}$ for both signs of charge. The signal for these channels turns off abruptly at the same altitude as the signals for channel 2+. The third pair of collecting plates has the largest bias potentials, $\pm 54 \mathrm{~V}$, which are the largest potentials in the instrument. The simultaneous occurrence of positive and negative particles raises the question of enhanced coagulation of particles with opposite signs of charge. Jensen and Thomas (1991) have shown that this effect is small. The channel collecting positive charge saturates at about $90 \mathrm{~km}$ altitude and remains saturated to about the same altitude on the downleg, Fig. 7. This saturation is probably due to a flux of positive ions through the air exit windows, which are covered by a screen mesh biased at $-10 \mathrm{~V}$. The mesh is designed to rebel electrons and collect light ions eliminating a collection of charged particles through the air exit windows (Knappmiller et al., 2008). However, the effective cross section of the collecting wires decreases with increasing temperature. This increases the probability that the ions will pass through the air exit windows and be collected by the $3+$ channel above the mesopause.

On the downleg of MASS1, channels 3+ and 3- showed only a small charge density from $80-87 \mathrm{~km}$. The channel collecting positive charge was saturated from about $89 \mathrm{~km}$ on the upleg to about $89 \mathrm{~km}$ on the downleg. The channel collecting negative charge showed a narrow layer with a charge number density of $\sim 800 \mathrm{~cm}^{-3}$ just below $88 \mathrm{~km}$. On the upleg, larger signals $\left(\sim 2000 \mathrm{~cm}^{-3}\right)$ were seen on both channels from $86-88 \mathrm{~km}$. The smaller signals are attributed to the cloud being weaker at the downleg location. 

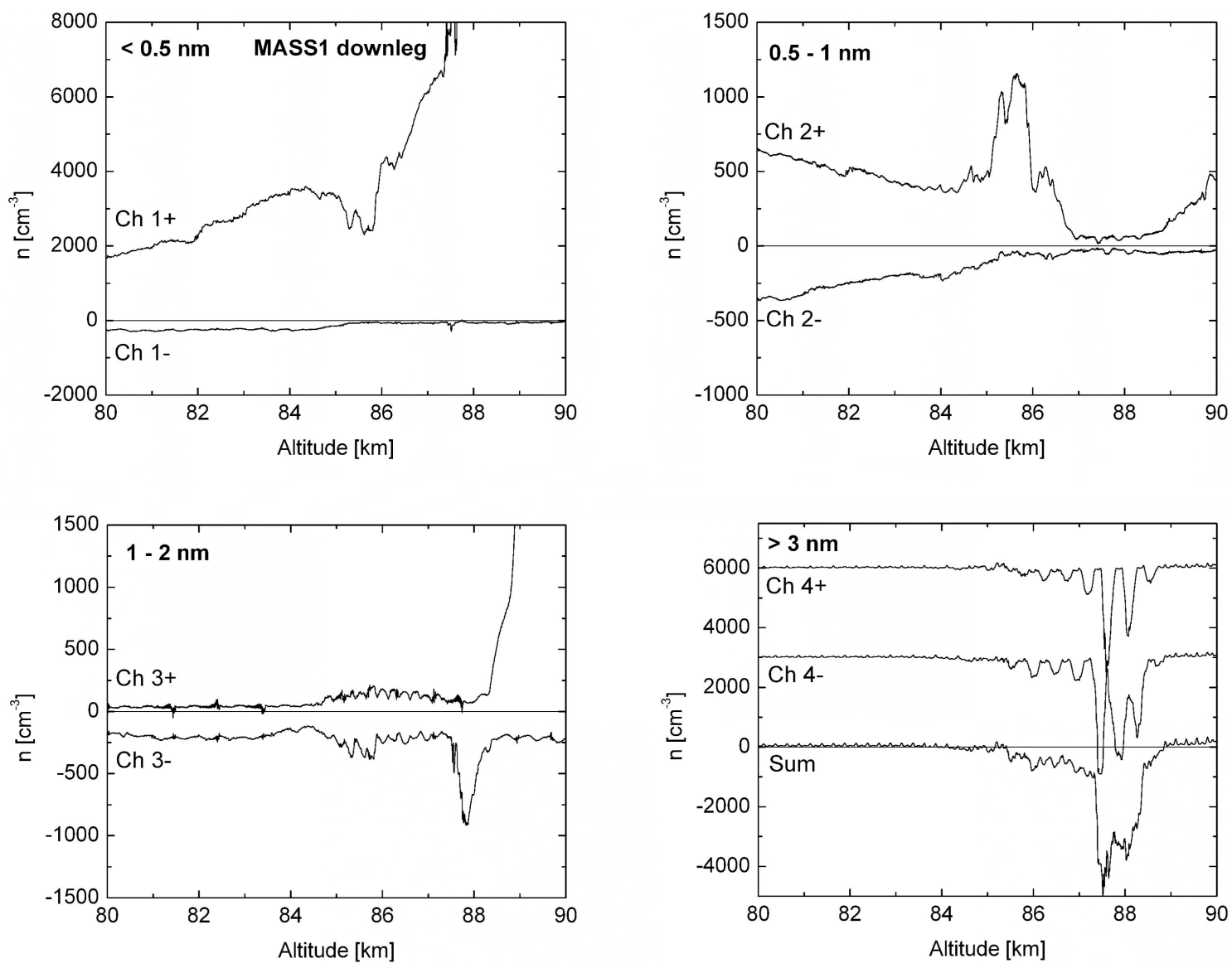

Fig. 7. Data from the 8 channels of the MASS instrument for the downleg of the first flight. Channels $4+$ and $4-$ are offset from zero for clarity and their sum is plotted correctly.

\subsection{Channels $4+$ and $4-(>3 \mathrm{~nm}$, nominally $)$}

The data from channels 4+ and 4- are shown both separately (with offsets) and summed in Fig. 6. The summation removes modulation at the rocket rotation frequency. The charge number density has a maximum value near $3000 \mathrm{~cm}^{-3}$ and the net charge is negative. There is an abrupt onset of particle collection at $83 \mathrm{~km}$ that is the location of the lowest peak in the radar data and the location of NLC seen in the lidar. The peak in the charge density at $86-88 \mathrm{~km}$ is near the peak at $88 \mathrm{~km}$ seen in the radar data and is near a secondary peak at $86 \mathrm{~km}$ seen in the lidar data. Particles with radii greater than $10 \mathrm{~nm}$ may be multiply charged so the number density of particles may be less than the number density of charge.

The signals from channels 4+ and 4- are oscillatory with a frequency of $\sim 2 \mathrm{~Hz}$ and are out of phase. The rocket rotation frequency is $2 \mathrm{~Hz}$, thus the oscillations are presumed to be caused by the incoming particles having a velocity vector that is not precisely aligned with the rocket axis. The origin of the modulation is likely to be a wind transverse to the rocket trajectory. The amplitude of the modulation of the signal by the rocket rotation is approximately $100 \%$. The stream of particles entering the opening is $28 \mathrm{~mm}$ in width and the distance from the opening to the bottom plates is $44.7 \mathrm{~cm}$. There is a $7 \mathrm{~mm}$ gap between the two plates, thus if the stream is undeflected and remains $28 \mathrm{~mm}$ in width, $10.5 \mathrm{~mm}$ of the stream falls on each plate. A deflection of $10.5 \mathrm{~mm}$ is then sufficient to remove the signal from the plate and create a $100 \%$ modulation. This deflection is $2.3 \%$ of the instrument height, indicating that a wind transverse to the rocket trajectory of $\sim 23 \mathrm{~m} / \mathrm{s}$ is sufficient to cause the modulation. This wind velocity is well within the range from ground-based measurements (Singer and Latteck, 2009).

The signals from channels 4+ and 4- being nearly equal indicate that the largest particles have traveled to the bottom of the instrument with relatively little deflection, thus their mass is significantly above the threshold of $\sim 90000 \mathrm{amu}$ for channels 4 found by the simulations (Table 1). The modulation of the signals being near $100 \%$ provides additional information regarding the aerosol particle size. If there were negative particles with radii in the range 3 to $7 \mathrm{~nm}$, then these would fall near the center of the collector plate for channel $4-$. The wind and rocket rotation would not displace 
these particles sufficiently to significantly modulate collection. Thus the depth of the modulation indicates that these signals are primarily from particles with radii $>7 \mathrm{~nm}$. Small deflections are insufficient to separate particles with positive and negative charge, thus for channels 4 there may be positively charged particles hidden by the signal from the more numerous negative particles.

Channels 4+ and 4- on the downleg of MASS1 are also shown in Fig. 7. As on the upleg, there is modulation of the signals by the rocket rotation. The negatively charged aerosols again fall about equally on the two bottom plates indicating a small deflection requiring radii $>7 \mathrm{~nm}$. The net charge number density reaches about $-4000 \mathrm{~cm}^{-3}$ from $87.5-88.5 \mathrm{~km}$. On the upleg, these largest particles were detected over a wider range of altitudes, $82-88 \mathrm{~km}$.

It is possible for neutral aerosol particles of ice to break into charged fragments and thereby create a false signal. Channels 4+ and 4- receive the heaviest charged particles as well as the undeflected neutral particles, thus for these plates the probability of spurious charge generation is greatest. If the neutral particles deposit negative charge on these plates, then fragments leaving the plates must carry an equal positive charge that could be detected. Channels $3+$ and $3-$ have the largest electrical bias $( \pm 54 \mathrm{~V})$ and thus are most likely to collect spurious charge generated within the instrument. The flight data show signals from impacts of heavy charged aerosols on channels 4 with a sharp rise at $83 \mathrm{~km}$. The signals on channels 3 show no onset of signal until $86 \mathrm{~km}$ indicating that at least from 83 to $86 \mathrm{~km}$ the charge collected on the fourth pair of collection plates generates no charged fragments that are collected by the third pair of plates. For other channels, there is no consistent correlations between channels that would indicate spurious current generation.

\section{MASS2 flight data}

\subsection{Launch conditions}

MASS2 (NASA designation 41.070) was launched 6 August 2007 at 22:56:00 UTC and reached an apogee of $131.6 \mathrm{~km}$. The rocket velocity dropped from $1077 \mathrm{~m} / \mathrm{s}$ at $80 \mathrm{~km}$ to $985 \mathrm{~m} / \mathrm{s}$ at $90 \mathrm{~km}$. The solar zenith angle was 94.3 degrees. The ALWIN radar, Fig. 3b, showed PMSE extending from 83 to $89 \mathrm{~km}$ with a peak at $87 \mathrm{~km}$. The ALOMAR RMR lidar, Fig. 4b, showed only a very weak scattering from aerosol particles with a peak backscatter coefficient of only $0.11 \pm 0.02 \times 10^{-10}(\mathrm{~m} \mathrm{sr})^{-1}$ at $83 \mathrm{~km}$ which is about 40 times lower than the level used for statistical investigation of NLC (Fiedler et al., 2009).

\subsection{Electron density}

The Faraday rotation data for electron density, Fig. 5b, show a nearly monotonic increase with altitude and there is no indication of a bite-out as was observed on the first flight. From
$88-95 \mathrm{~km}$, the positive ion density is near to the electron density. Faraday rotation data were not obtained above $95 \mathrm{~km}$ for MASS2. A significant difference between the MASS1 data and MASS2 data is the absence of a bite-out for MASS2. At $87 \mathrm{~km}$ the ALWIN radar peak coincides with the sharp change in the electron and ion density. The edges of the PMSE, however, do not coincide with any details in the electron or ion densities. The discrepancies between electron and ion densities below $87 \mathrm{~km}$ are again attributed to uncertainty of wave propagation due to a large collision frequency and the uncertainty in the collection efficiency of the ions.

\subsection{Channels 1-4}

The MASS instruments channels for the upleg and downleg of MASS2 are shown in Figs. 8 and 9, respectively. Channel $2+$ gave zero signal during the entire flight indicating a malfunction. If the signal was lost from an open circuit to telemetry, the MASS instrument operated normally on the other channels. If the connection to the collection plate failed, then the bias voltage did not appear on the collection plate and the deflection of the particles was changed. The greatest deflection voltage is from the voltage on the third pair of deflection plates which operated normally, thus the signals on channels 3 and 4 would have only a small change in the range of detected mass if the $-5.4 \mathrm{~V}$ bias on channel $2+$ was absent. Channels $1+$ and $1-$ gave signals which appear to be unaffected.

Channel $1+$ indicates above $87 \mathrm{~km}$ a smoothly increasing positive ion density that is consistent with electron densities from Faraday rotation (see Fig. 5). Near $87 \mathrm{~km}$ there is a superimposed charge layer that is incrementally $\sim 5000 \mathrm{~cm}^{-3}$ (Fig. 8). The channel 1- data show a charge layer between 86 and $88 \mathrm{~km}$. These are in the mass range 200-900 amu at $90 \mathrm{~km}$ if the payload potential is $-1 \mathrm{~V}$ (see Table 1). The channel 2- data show negative aerosol particles similar in density to those seen by MASS1 and with a similar reduction in density above $86 \mathrm{~km}$. In the channel $3+$ data, the number density is near $2000 \mathrm{~cm}^{-3}$ with a narrow spike that reaches $4000 \mathrm{~cm}^{-3}$. The density of these positive particles falls abruptly at $87 \mathrm{~km}$ coincident with an abrupt rise from channel $1+$ collecting the lightest positive particles, thus indicating a shift of positive charge to particles of lower mass. In the channel 3- data, the number density reaches a maximum near $5000 \mathrm{~cm}^{-3}$, which is larger than the number seen in the NLC conditions of the first flight. These particles extend to lower altitude than the larger $>3 \mathrm{~nm}$ particles. A significant difference from MASS1 is the much lower density of the largest particles recorded by channels $4+$ and 4-, $\sim 500 \mathrm{~cm}^{-3}$ rather than $\sim 3000 \mathrm{~cm}^{-3}$. The range of altitude $(86.5-87.5 \mathrm{~km})$ is also much smaller. The relatively small number of particles $>3 \mathrm{~nm}$ is consistent with the absence of significant lidar returns. The large signals on the channels for $1-2 \mathrm{~nm}$ relative to the other channels indicate that these 

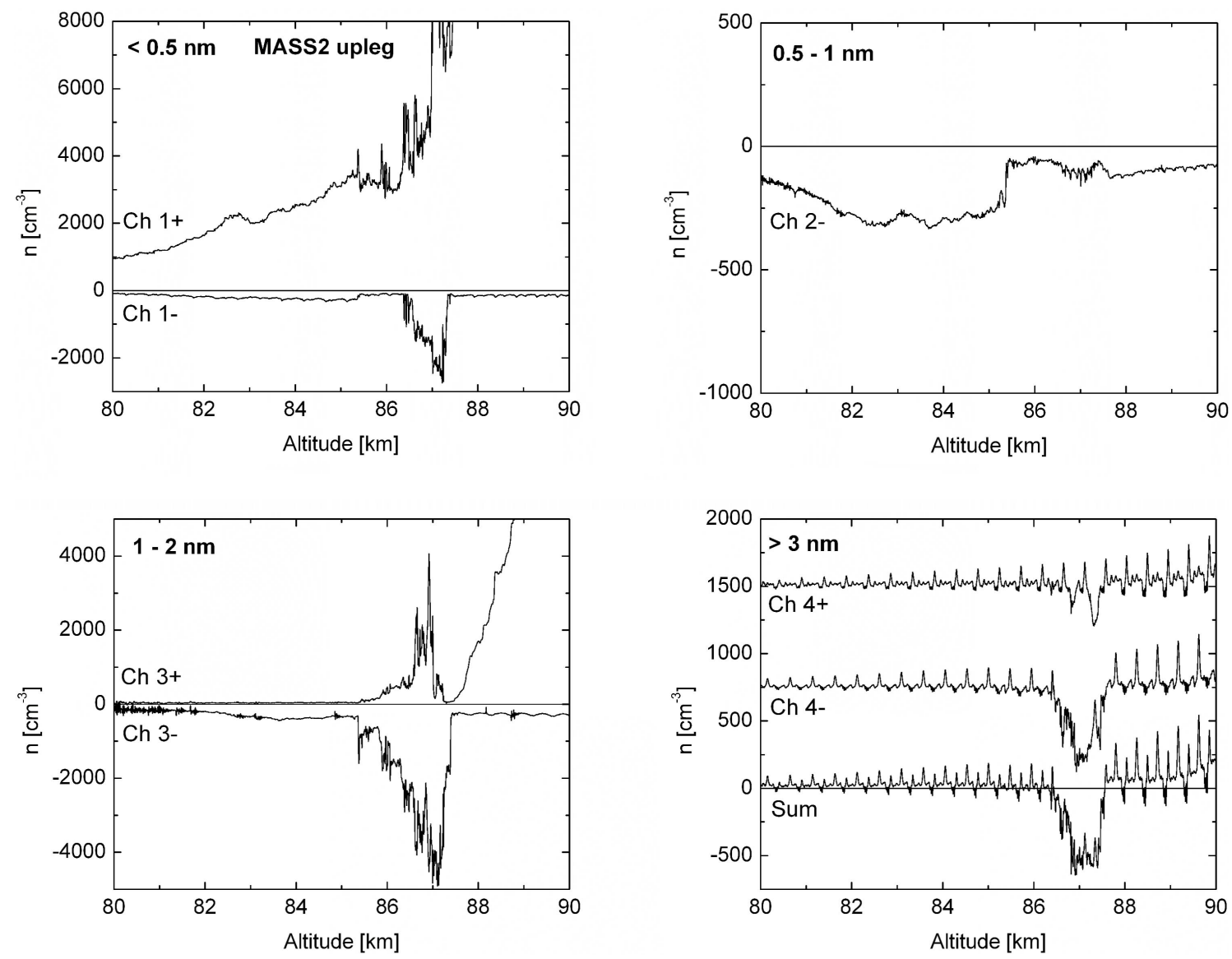

Fig. 8. Data from 7 of the 8 channels of the MASS instrument for the upleg of the second flight. Channels 4+ and 4- are offset from zero and their sum is plotted correctly. Channels 4 appear noisy because the vertical scale spans a smaller range than in Figs. 6 and 7.

smaller particles are most likely responsible for the PMSE observed at the time of launch.

On the downleg, Fig. 9, the indications of charge layers are smaller in magnitude and vertical extent. Channel $1-$ for the lightest negative aerosol particles shows negligible signal. Channels 3 - for particles nominally $1-2 \mathrm{~nm}$ shows a maximum of $\sim 3000 \mathrm{~cm}^{-3}$ in a narrow charge layer at $86.5 \mathrm{~km}$. Channel 4- shows a much smaller number density similar to that seen on the upleg, but narrower in extent. Indications of positive charge layers are absent in Channel 1+. Channel 3+ saturates above $\sim 88 \mathrm{~km}$ on the upleg and downleg of both flights, which is presumed to be "leakage" of ions into the instrument through the air exit windows.

\section{Discussion}

\subsection{Quasineutrality check for MASS1 and MASS2}

The sum of the charge densities from all MASS channels should be zero if all charged species are collected. The collection of electrons is prevented by the rocket potential. Thus a zero sum is only expected with the inclusion of the electron density from the Faraday rotation antennas. Positive charge density, negative charge density, and their sum are plotted in Fig. 10 for the uplegs of both flights. The downleg sums are omitted as the Faraday rotation antennas are not oriented to measure the electron density on the downleg. The positive charge density is obtained by summing the signals on the three negatively biased collecting plates of the MASS instrument. The negative charge density is obtained by summing the signals on the three positively biased plates, the two unbiased plates that receive the heaviest particles, and the electron density signal from the Faraday rotation antennas. The sum of all signals is near zero from 83 to $86 \mathrm{~km}$ for the upleg of MASS1. Below $83 \mathrm{~km}$, there is a net collection of positive charge, presumed to be a result of light negative aerosols being repelled by the rocket charging potential or missing electrons from the Faraday rotation measurement due to poor spatial resolution. The charge imbalance at $86 \mathrm{~km}$ appears to be associated with a peak in the positive and negative charge on the 1-2 nm MASS channels. Above $87 \mathrm{~km}$ the electron density "tracks" the ion density from channel 1+ (Fig. 5), however, the electron density misses the small scale structures which appear in the ion density. At $90 \mathrm{~km}$ the $3+$ 

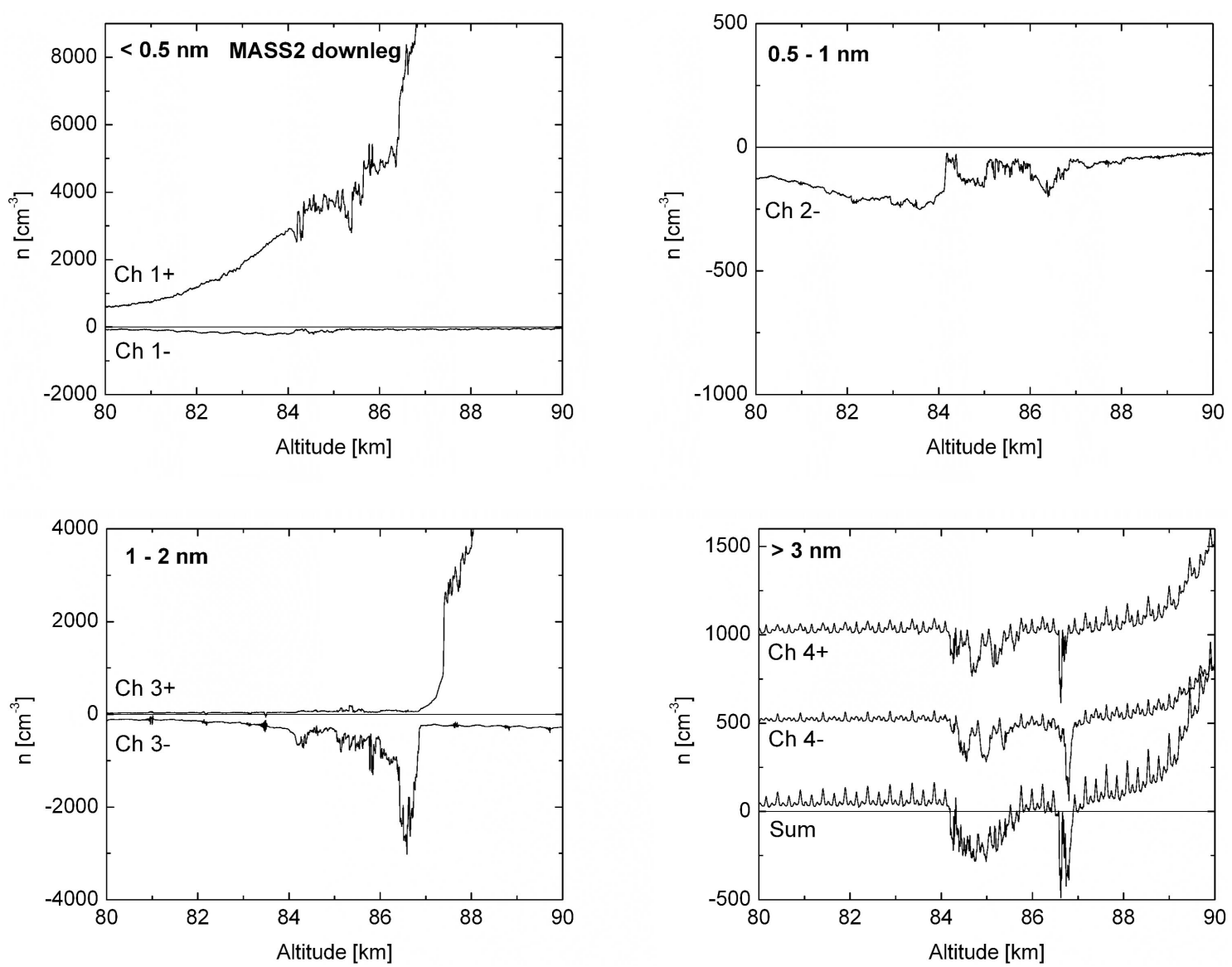

Fig. 9. Data from 7 of the 8 channels of the MASS instrument for the downleg of the second flight. Channels 4+ and 4- are offset from zero and their sum is plotted correctly.

channel of the MASS instrument begins to saturate, possibly due to the collection of positive ions through the air exit windows. At this point, the sum of the signals diverges from quasineutrality.

In the MASS2 upleg the sum of all negative and positive densities yields nearly a zero net charge collection until $86 \mathrm{~km}$ where the signal begins to go negative. The overall positive signal below $86 \mathrm{~km}$ is a result of the MASS2 instrument missing small negatively charged particles or from the Faraday rotation underestimating the electron density. The sum becoming negative at $86 \mathrm{~km}$ may be due to the missing channel 2+ signal which was significant in the cloud layer on the MASS1 flight. Above $89 \mathrm{~km}$, the signal is again affected by the saturation of channel $3+$.

\subsection{Positive ions}

Channel 1+ collects light molecular ions and cluster ions and thus the data from this channel should be consistent with previous data from rocket-borne ion mass spectrometers. The instruments have shown that the dominant light ions are $\mathrm{NO}^{+}$ and $\mathrm{O}_{2}^{+}$in the absence of NLC (Kopp and Herrmann, 1984).
Depletion of positive ions has been observed within NLC (Balsiger et al., 1996) and is seen at $86-88 \mathrm{~km}$ in the Channel 1+ data for the MASS1 upleg. In NLC conditions, a transition height is observed at about $90 \mathrm{~km}$ (Kopp et al., 1985; Björn et al., 1985). Below this transition, the dominant positive ions are the cluster ions $\mathrm{H}^{+}\left(\mathrm{H}_{2} \mathrm{O}\right)_{n}$ with $n=1-20$ being in the range detectable by the ion mass spectrometers. In the MASS1 data, there is a ledge at $88 \mathrm{~km}$ in channels $2-4$ that we interpret to be this transition. The increase in the channel $1+$ signal at $88 \mathrm{~km}$ could be from the reappearance of molecular ions, however, this channel is also sensitive to the smaller cluster ions.

\subsection{Negative species}

Channel 1- for the upleg of MASS1 has a signal level that is very small below and above the PMSE region where the Faraday rotation indicates measurable electron densities. This indicates that electron collection is suppressed by the rocket potential and the electrons' high thermal velocities. An ion mass spectrometer configured to record negative ions in a high-pass mode (Schulte and Arnold, 1992) was flown in 

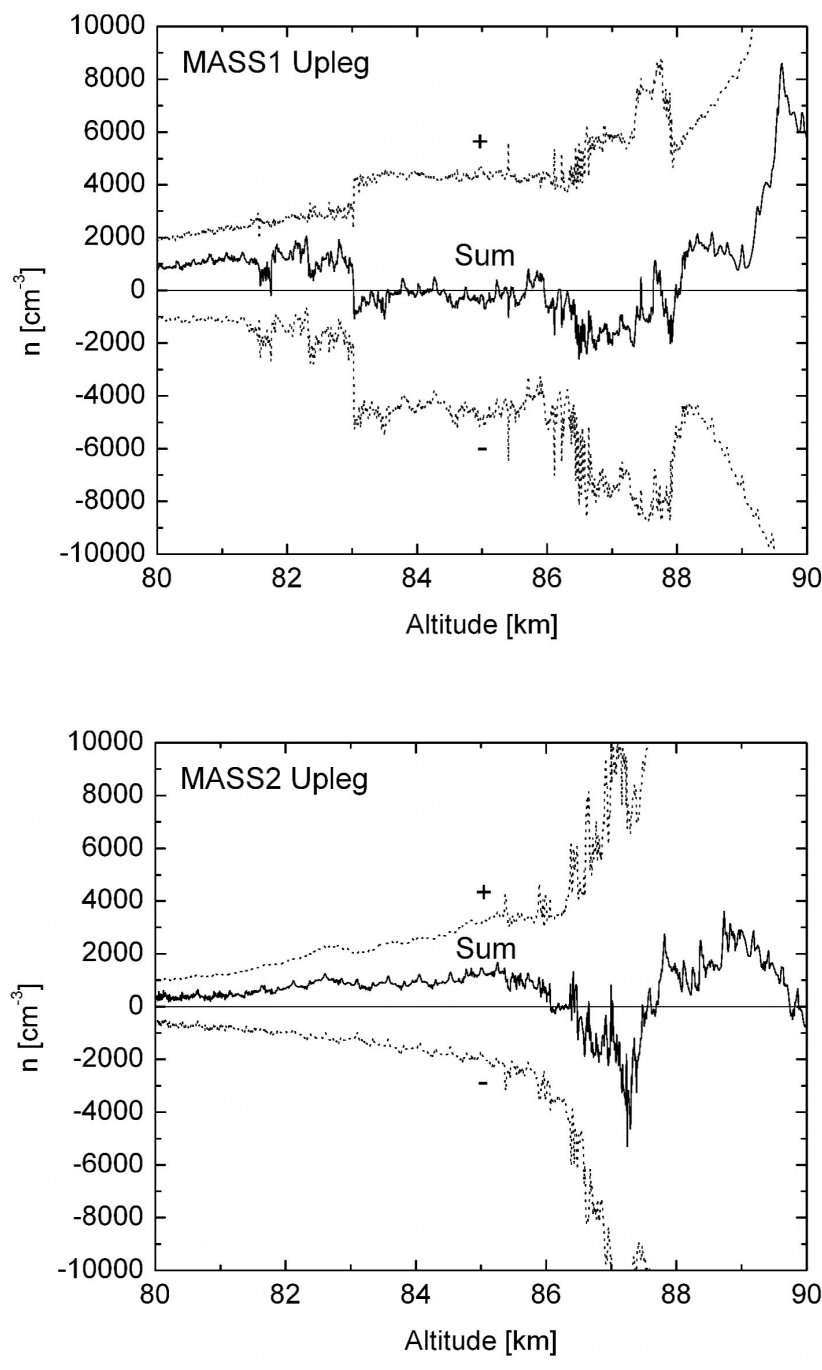

Fig. 10. These plots show, for the upleg and downleg of MASS1 and MASS2, the sum of the channels with positive signals $(+)$, the sum of the channels with negative signals $(-)$, and the sum of all channels (sum). A zero sum is consistent with all charges having been collected, which is the nearly the case for MASS1 upleg from 83 to $86 \mathrm{~km}$.

1982 as a part of the CAMP (Cold Arctic Mesopause Project) campaign. The mass cutoff could be scanned from 0 to $473 \mathrm{amu}$. The negative ions with mass below $100 \mathrm{amu}$ were attributed to negative molecular ions. The small signals that are seen from $83-86 \mathrm{~km}$ on channel $1-$ may be due to the light negative ions seen previously by the negative ion mass spectrometer. The assumed negative rocket potential results in a mass threshold for the first channel that changes from $\sim 30 \mathrm{amu}$ at $80 \mathrm{~km}$ to $\sim 200 \mathrm{amu}$ at $90 \mathrm{~km}$. Above $78 \mathrm{~km}$, masses greater than $473 \mathrm{amu}$ were dominant in the data from the negative ion mass spectrometer and it was suggested that these might be meteoric smoke particles. Mass analyzers determine only the charge-to-mass ratio and cannot distinguish between NLC particles and smoke particles. Thus it is difficult to unambiguously identify negative meteoric smoke particles in NLC regions.

\subsection{Positive charge on the smallest particles}

The MASS instrument data show that the heaviest particles (seen by channels 4) have net negative charge. Channels 2 and 3 for lighter particles show that at $85-88 \mathrm{~km}$ positively charged particles are present (with the exception of MASS2 downleg data). In this section we discuss the processes and scenarios that can result in positive charge on the smallest particles and negative charge on the largest particles.

The measurement of significant numbers of positively charged aerosol particles of any size is unexpected from the theory of aerosol charging in plasma. In the absence of biteout conditions, aerosol particles have a rate of electron attachment that is much higher than the rate of ion attachment. Aerosol particles below about $10 \mathrm{~nm}$ in radius primarily make transitions between having $Z=0$ and $Z=-1$, where $Z$ is the number of elementary charges. The low rate for ion collection relative to that for electrons results in the time in the $Z=-1$ state being orders of magnitude longer than the time in the $Z=0$ state, and the state $Z=+1$ lifetime is negligible, relatively. For particles greater than $10 \mathrm{~nm}$ in radius, multiple charging is possible and the most probable charge is more negative than $Z=-1$ (Rapp and Lübken, 2001). Thus the occurrence of positive charge layers must have an explanation outside the usual theoretical framework of charge equilibrium.

The first possibility is that the positive charge on small particles is due to suppressed electron collection. The charging of aerosol particles by ion capture is possible under very strong bite-out conditions when essentially no free electrons are present to neutralize the positive charge (Rapp and Lübken, 2001). In the MASS1 data, however, there is an abundance of $>3 \mathrm{~nm}$ negatively charged particles coexisting with the smaller positive ones. The ions are much more likely to attach to larger negative aerosol particles than to small neutral ones. Thus the size dependence of the observed charge distribution is not consistent with plasma charging.

The second possibility is enhancement of photoelectron emission. The photoelectron charging rate of a particle with radius $r$ is calculated from

$R_{p h}(r)=\pi r^{2} \int Q(r, \lambda) F(\lambda) Y(\lambda) d \lambda$,

where $Q(a, \lambda)$ is the absorption cross section, $F(\lambda)$ is the solar spectrum, $Y(\lambda)$ is the photoelectron yield and the integration is performed over the range of wavelengths $\lambda$ that may contribute to photoemission (Turco et al., 1982; Rapp and Lübken, 1999). In theory, $R_{p h}(r)$ for nanometer sized icy aerosol particles is very small due to the large work function of ice and small absorption cross section, however, the icy particles may be contaminated by $\mathrm{Na}$ or $\mathrm{Fe}$ that can significantly lower the work function (e.g. Rapp and Lübken, 
1999). Vondrak et al. (2006a, b) have shown by laboratory experiments that a minor contamination of ice by $\mathrm{Na}$ can enhance the photoelectric effect by orders of magnitude and reduce the work function from $8.7 \mathrm{eV}$ to about $2.3 \mathrm{eV}$. An upper estimate of the photoelectron emission rate can be calculated by including the solar spectrum up to $\lambda=540 \mathrm{~nm}(2.3 \mathrm{eV})$ and choosing $Y=1$ for all wavelengths. The latter choice means that all photons with energy above the work function that interact with the particle will induce photoelectron emission. Because of the small size parameter, $\alpha=2 \pi r / \lambda \ll 1$, the Rayleigh scattering cross section,

$Q(r, \alpha)=\pi r^{2} \frac{8}{3} \alpha^{4}\left(\frac{m^{2}-1}{m^{2}+2}\right)^{2}$,

is used in Eq. (1). Parameter $m=1.31$ is the refractive index of water ice. The photoelectron emission rate calculated for a solar cycle minimum condition is $R_{p h} \approx 9 \times 10^{-5} \mathrm{~s}^{-1}$ for $r=1 \mathrm{~nm}$ particle, which is much lower than the electron capture rate. The two charging rates become comparable at $r=2 \mathrm{~nm}$ particle radius only with strong bite-out conditions in which $99 \%$ of the electrons attached to aerosol particles. We conclude that photoelectron emission is likely not playing a significant role in the positive charge observed on small particles (channels $2+$ and $3+$ ) for the following reasons. First, the photoemission rate is too small to charge particles $1 \mathrm{~nm}$ or smaller in size, even with a lowering of the work function. Second, the Rayleigh scattering cross section increases strongly with size and the large particles rather than the small ones would be charged positively. Third, the number density of $\mathrm{Na}$ necessary to lower the work function is very small relative to the water vapor. This means that only a small fraction of 0.5-2 $\mathrm{nm}$ aerosol particles can be contaminated by $\mathrm{Na}$ and have a lowered work function.

It has been reported that the yield of photoelectron emission from nanometer sized particles may be increased by two orders of magnitude over the yield from a planar surface (Schmidt-Ott et al., 1980), however, this effect has been explained as a plasmon resonance that occurs only for highlyconducting metallic particles and films (Tsang et al., 1991).

The third possibility for the positive particles is that the particles grew from positive condensation nuclei (Arnold, 1980; Turco et al., 1982; Sugiyama, 1994, 1995; Gumbel et al., 2003). In this case, small molecular ions or cluster ions act as the condensation nuclei. As the particles grow they are neutralized $(Z=0)$ by electron capture and later charge negatively $(Z=-1)$ by collecting an additional electron. This scenario can explain the occurrence of positively charged aerosol particles in the smallest size ranges and negative particles at the largest sizes. The requirement for this to occur is that the positively charged particles have time to grow to the observed size (1-2 $\mathrm{nm}$ ) before being neutralized. The growth rate for a highly supersaturated water vapor is given by (Hes-

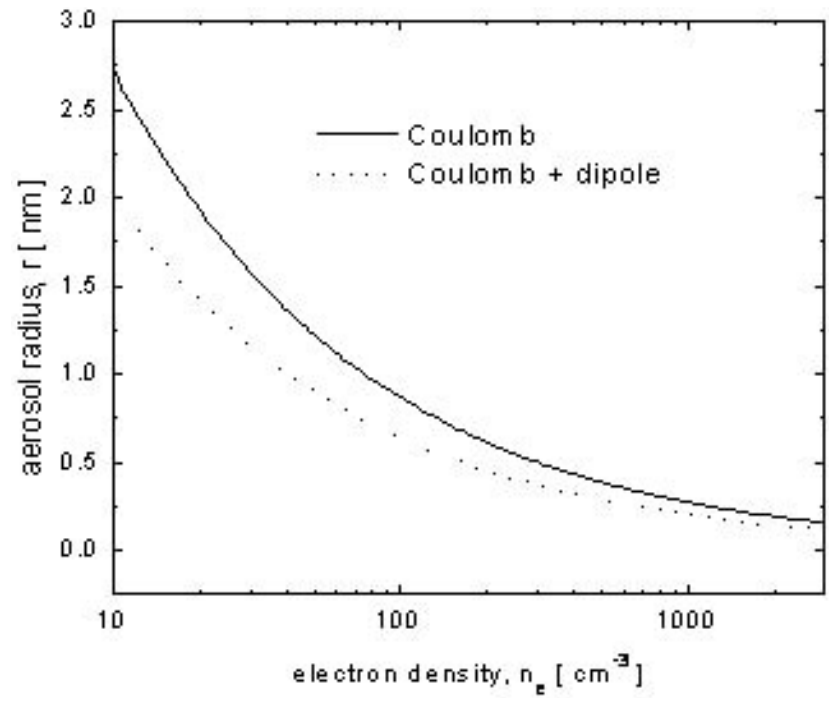

Fig. 11. The size of the positive aerosol particle when it is neutralized by capturing an electron as a function of electron density. The solid line for a charging model with only the Coulomb force and the dotted line is for a model with both the Coulomb force and the dipole force.

stvedt, 1969)

$\frac{\partial r}{\partial t} \cong \frac{F}{\rho}\left(\frac{m}{2 \pi k T}\right)^{1 / 2} w P$,

where $F=0.83$ is the condensation ratio for water vapor, $\rho$ is the specific weight of ice, $m$ is the mass of water molecules, $w$ is the water mixing ratio and $P$ is the pressure at the altitude of interest. The rate of electron capture by the singly charged positive particle is (Natanson, 1960)

$R_{e}(r) \cong \pi r^{2} n_{e} v_{e} \frac{q^{2}}{4 \pi \varepsilon_{0} r k T}$,

where $n_{e}$ is the free electron density and $v_{e}=\sqrt{8 k T / \pi m_{e}}$ is the electron average speed. As the particle grows the probability of capturing an electron is increasing. The characteristic neutralization time $\tau$ can be calculated from the condition

$$
\int_{0}^{\tau} R(r(t)) d t=1 .
$$

This equation is solved for typical conditions at $87 \mathrm{~km}$ altitude, where the layer of light positive aerosol particles is observed. The temperature $T=135 \mathrm{~K}$ and neutral pressure $P=0.243 \mathrm{~Pa}$ are taken from Lübken (1999) for the date of the launch and $w=3 \mathrm{ppm}$ mixing ratio of water vapor is assumed. Figure 11 shows the most probable radius of the positive aerosol particle at the time it captures an electron from Eq. (5). The dotted line is the same calculation including the dipole interaction as well as the Coulomb interaction between the electron and the positively charged aerosol particles (Robertson and Sternovsky, 2008). The requirement 

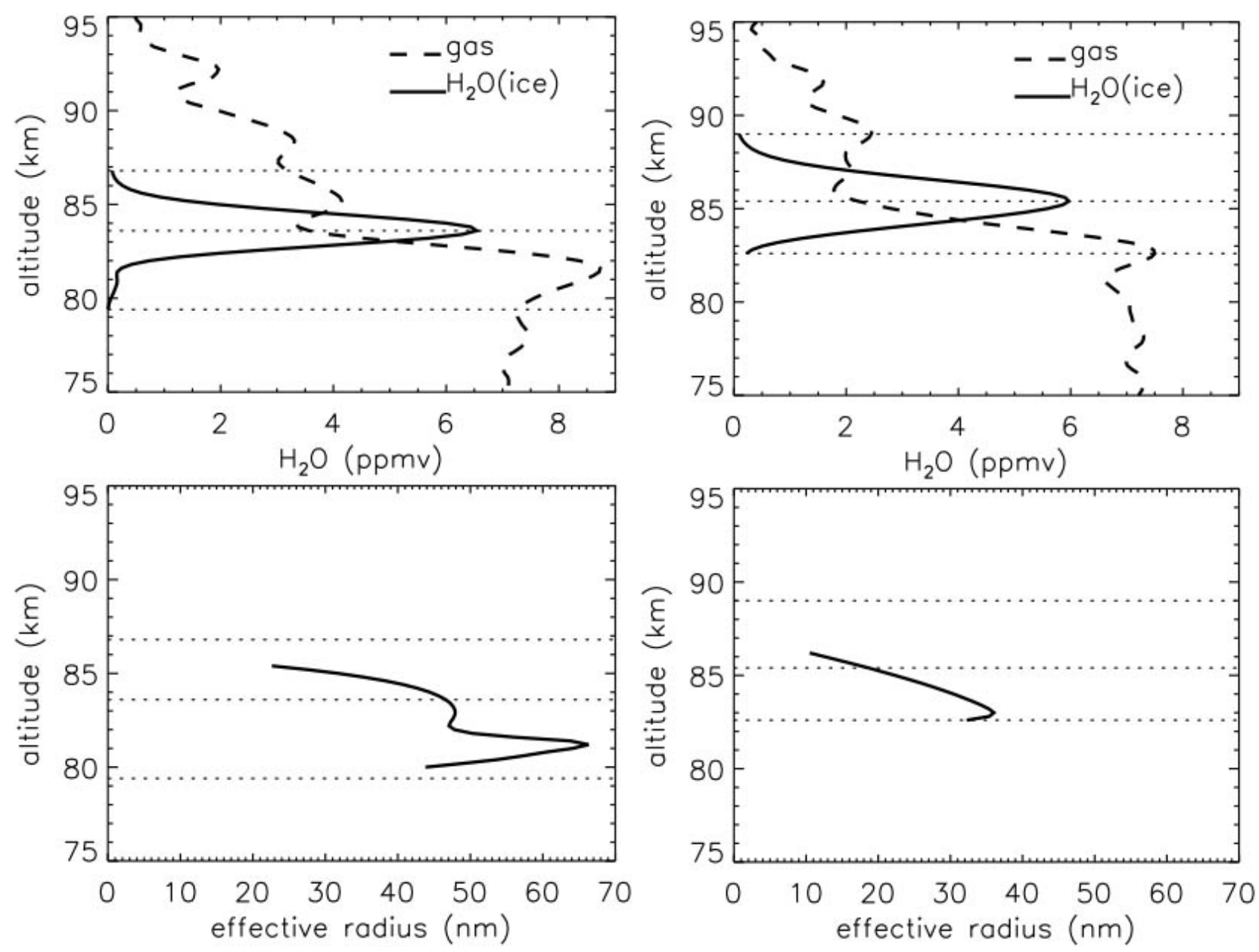

Fig. 12. SOFIE observations on 3 August 2007 nearest to the MASS 1 flight, $20: 35$ UTC at $71.3^{\circ} \mathrm{N}, 30.4^{\circ} \mathrm{E}$ (left panel) and at $22: 12 \mathrm{UTC}$ at $71.3^{\circ} \mathrm{N}, 6.3^{\circ} \mathrm{E}$ (right panel). Horizontal dotted lines indicate $Z_{\mathrm{top}}, Z_{\mathrm{max}}$, and $Z_{\text {bot }}$ determined from $\mathrm{H}_{2} 0$ (ice).

for the neutralized particle to continue to growth is that it have the critical radius for condensation $(\sim 0.5 \mathrm{~nm})$ (Megner and Gumbel, 2009; Gumbel and Megner, 2009). Figure 11 shows that positive nuclei can grow to critical size provided that there is a strong bite-out that reduces the electron density to about $100 \mathrm{~cm}^{-3}$. Additional modeling is needed to show that the transition from an initial state with high electron density to one of low electron density can occur.

An alternate scenario for nucleation is that it occurs on meteoritic smoke particles. Recent modeling of meteoric smoke production and circulation shows that the smoke particles are carried away from the summer pole by circulation (Megner et al., 2006, 2008; Bardeen et al., 2008). Models for condensation require a minimum particle radius near $0.5 \mathrm{~nm}$ for typical conditions (Keesee, 1989; Megner et al., 2008; Gumbel and Megner, 2009; Winkler et al., 2008). Circulation models indicate that nanometer-sized meteoric condensation nuclei are likely to have summer densities of order $1 \mathrm{~cm}^{-3}$ which is far too low to account for the charged fraction of nanometer-sized particles observed by rocket-borne probes. Meteoritic particles should charge negatively because of the larger thermal velocity of electrons, thus if these were the condensation nuclei the smallest particles should have negative charge and growth on these would not account for the observation of positively charged particles.

\subsection{Photometer data and the altitude dependence of particle size}

Information about the visible NLC complementary to the ground-based lidar is available from the onboard photometer (Megner et al., 2009). This measurement provides the profile of the scattered sunlight from which the vertical structure of the ice particle layer is obtained. The upward-looking photometer provides data on the upleg. On the downleg, the photometer is saturated by the bright lower atmosphere. The photometer on MASS1 detected an unusually high and extended NLC, and confirmed the presence of ice particles 
from $\sim 81$ to $\sim 88 \mathrm{~km}$. The cloud penetrated by the rocket showed three distinct peaks of comparable brightness, with the highest at $\sim 86 \mathrm{~km}$. This structure is thus broader than any NLC previously reported by in situ measurements. The photometer measurements on MASS2 showed no NLC at the point of passage. In addition to the exact altitude range of the NLC, the photometer measurement provides an optical analysis of cloud particle sizes through the angular dependence of the scattering signal, i.e. the scattering phase function (Gumbel and Witt, 2001). Results from this analysis are discussed by Megner et al. (2009).

\subsection{Comparison with SOFIE limb scans}

The SOFIE (Solar Occultation for Ice Experiment) instrument on the AIM satellite measures atmospheric extinction at eleven wavelengths from 0.330 to $5.01 \mu \mathrm{m}$, in addition to temperature and the abundance of five gaseous species $\left(\mathrm{O}_{3}\right.$, $\mathrm{H}_{2} \mathrm{O}, \mathrm{CO}_{2}, \mathrm{CH}_{4}$, and NO) (Gordley et al., 2008). SOFIE multi-wavelength ice extinction measurements are used to determine ice mass density, particle shape, effective radius, and the parameters of a Gaussian particle size distribution (Hervig et al., 2009). The infrared ice extinction is proportional to the cube of the particle radius and is thus a direct measure of ice volume density. The field of view is $1.6 \mathrm{~km}$ vertically and $4.3 \mathrm{~km}$ horizontally, and the sample volume length is $\sim 290 \mathrm{~km}$ along the limb view. The two SOFIE limb scans nearest to MASS1 launch on 3 August were taken at $71.3^{\circ} \mathrm{N}, 30.4^{\circ} \mathrm{E}(20: 35 \mathrm{UTC})$ and $71.3^{\circ} \mathrm{N}, 6.3^{\circ} \mathrm{E}$ (22:12 UTC), and the two nearest to the MASS2 launch on 6 August were taken at $72.0^{\circ} \mathrm{N}, 22.6^{\circ} \mathrm{E}(21: 02 \mathrm{UTC})$ and $72.0^{\circ} \mathrm{N}, 358.4^{\circ} \mathrm{E}$ (22:39 UTC). SOFIE observations of water vapor and the gas phase equivalent $\mathrm{H}_{2} \mathrm{O}$ contained in the ice phase, $\mathrm{H}_{2} \mathrm{O}$ (ice), are shown in Fig. 12 for profiles near Andøya on 3 August, where altitudes of the ice layer top $\left(Z_{\text {top }}\right)$, bottom $\left(Z_{\text {bot }}\right)$, and peak $\mathrm{H}_{2} \mathrm{O}$ (ice) $\left(Z_{\text {max }}\right)$ are indicated. These observations indicate bright NLCs, with $\mathrm{H}_{2} \mathrm{O}$ (ice) from 5 to 6 ppmv. Ice particle effective radii ranged from $25-50 \mathrm{~nm}$ at $Z_{\max }$, with the largest particles occurring below $Z_{\max }$. Existence of the largest ice particles below $Z_{\max }$ is consistent with the lidar observations of Baumgarten and Fiedler (2008). The 6 August observations (Fig. 13) indicate more tenuous NLCs than on 3 August, with less than $\sim 2$ ppmv $\mathrm{H}_{2} \mathrm{O}$ contained in the ice phase. The ice extinctions on 6 August were too low to produce a useable signal in the near-infrared channels of the instrument, and thus particle size could not be retrieved.

The SOFIE data and the rocket data are not within a common volume, the PMSE data for the two dates are highly variable, and the data from the MASS instrument differs on upleg and downleg. Thus a comparison between the rocket data and SOFIE is only marginally justified. The MASS instrument data channels 4+ and 4- have signals from the largest radius particles that are most responsible for extinction. These channels show on the upleg for 3 August the presence of ice
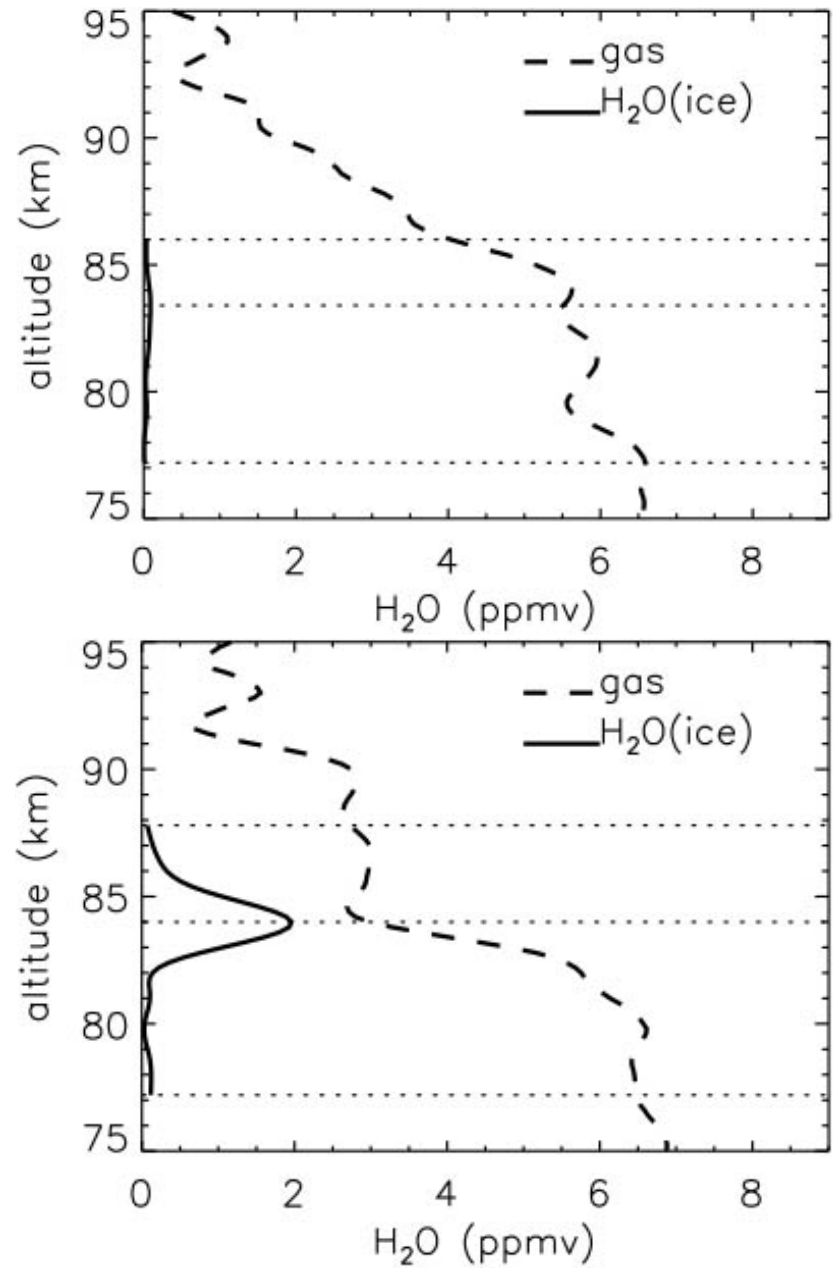

Fig. 13. SOFIE observations on 6 August 2007 nearest to the MASS2 flight, 21:02 UTC at $72.0^{\circ} \mathrm{N}, 22.6^{\circ} \mathrm{E}$ (top graph) and 22:39 UTC, at $72.0^{\circ} \mathrm{N}, 358.4^{\circ} \mathrm{E}$ (bottom graph). Horizontal dotted lines indicate $Z_{\text {top }}, Z_{\max }$, and $Z_{\text {bot }}$ determined from $\mathrm{H}_{2} O$ (ice).

particles with density $\sim 3000 \mathrm{~cm}^{-3}$ in the altitude range $83-$ $88 \mathrm{~km}$ which is near to the range of ice determined by optical extinction on the 22:12 UTC overpass.

\section{Summary and conclusion}

The MASS multichannel aerosol mass spectrometer has provided for the first time simultaneous measurements of the charge density residing on both positive aerosol particles and negative aerosol particles in four mass ranges. The data for the MASS1 upleg on 3 August 2007 into NLC and PMSE indicate that the smaller aerosol particles $(0.5-1 . \mathrm{nm}$ and $1-2 \mathrm{~nm})$ are predominately positively charged and that the larger particles $(>3 \mathrm{~nm}$ ) have predominately negative charge. The transition of the sign of charge from positive at the smaller sizes to negative at the larger sizes can be explained 
by positive ions or cluster ions being the condensation nuclei and subsequent collection of electrons after growth to a radius of $1-2 \mathrm{~nm}$. This scenario requires the reduction in electron density to $\sim 100 \mathrm{~cm}^{-3}$ in order to lengthen the time for positive charge to be neutralized by electron collection. A reduction of this order is observed in the data from the Faraday rotation instrument. Additional modeling including time-dependence of the aerosol particle charge is needed to show how the observed charge distribution could evolve from an initial state without the bite-out.

Acknowledgements. The authors acknowledge support from the Suborbital Program of the National Aeronautics and Space Administration (NASA), the Wallops Flight Facility of NASA, the Andøya Rocket Range, and the Austrian Science Fund.

Topical Editor C. Jacobi thanks A. M. Zadorozhny and another anonymous referee for their help in evaluating this paper.

\section{References}

Amyx, K., Sternovsky, Z., Knappmiller, S., Robertson, S., Horányi, M., and Gumbel, J.: In-situ measurement of smoke particles in the wintertime polar mesosphere between 80 and $85 \mathrm{~km}$ altitude, J. Atmos. Sol. Terr. Phys., 70, 61-70, 2008.

Andersson, P. U. and Pettersson, J. B. C.: Ionization of water clusters by collision with graphite surfaces, Z. Phys. D, 41, 57-62, 1997.

Arnold, F.: Ion-induced nucleation of atmospheric water vapor at the mesosphere, Planet. Space Sci., 28, 1003-1009, 1980.

Balsiger, F., Kopp, E., Friedrich, M., Torkar, K. M., Wälchi, U., and Witt, G.: Positive ion depletion in a noctilucent cloud, Geophys. Res. Lett., 23(1), 93-96, 1996.

Bardeen, C. G., Toon, O. B., Jensen, E. J., Marsh, D. R., and Harvey, V. L.: Numerical simulations of the three-dimensional distribution of meteoric dust in the mesosphere and upper stratosphere, J. Geophys. Res. 113, D17202, doi:10.1029/2007JD009515, 2008.

Baumgarten, G. and Fiedler, J.: Vertical structure of particle properties and water content in noctilucent clouds, Geophys. Res. Lett., 35, L10811, doi:10.1029/2007GL033084, 2008.

Baumgarten, G., Fiedler, J., Lübken, F.-J., and von Cossart, G.: Particle properties and water content of noctilucent clouds and their interannual variation, J. Geophys. Res., 113, D06203, doi:10.1029/2007JD008884, 2008.

Baumgarten, G., Fiedler, J., Fricke, K. H., Gerding, M., Hervig, M., Hoffmann, P., Müller, N., Pautet, P.-D., Rapp, M., Robert, C., Rusch, D., von Savigny, C., and Singer, W.: The noctilucent cloud (NLC) display during the ECOMA/MASS sounding rocket flights on 3 August 2007: morphology on global to local scales, Ann. Geophys., 27, 953-965, 2009, http://www.ann-geophys.net/27/953/2009/.

Bird, G. A.: Molecular Gas Dynamics and the Direct simulation of Gas Flows, Oxford University Press, New York, 1994.

Björn, L. G., Kopp, E., Hermann, U., Eberhardt, P., Dickinson, P. H. G., Mackinnon, D. J., Arnold, F., Witt, G., Lundin, A., and Jenkins, D. B.: Heavy ionospheric ions in the formation process of noctilucent clouds, J. Geophys. Res., 90(D5), 7985-7981, 1985.

Blix, T. A., Bekkeng, J. K., Latteck, R., Lübken, F.-J., Rapp, M., Schöch, A., Singer, W., Smiley, B., and Strelnikov, B.:
Rocket probing of PMSE and NLC - Results from the recent MIDAS/MACWAVE campaign, Adv. Space Res., 31(9), 20612067, 2003.

Bragin, Yu. A. and Shamakhov, B. F.: Direct studies of heavy positive ions (1-2000 amu) in the upper mesosphere, Kosmicheskie Issledovaniya, 20, 644-645, 1982 (in Russian).

Croskey, C. L., Mitchell, J. D., Friedrich, M., Torkar, K. M., Hoppe, U.-P., and Goldberg, R. A.: Electrical structure of PMSE and NLC regions during the DROPPS program, Geophys. Res. Lett., 28, 1427-1430, 2001.

Croskey, C. L., Mitchell, J. D., Goldberg, R. A., Blix, T. A., Rapp, M., Latteck, R., Friedrich, M., and Smiley, B.: Coordinated investigation of plasma and neutral density fluctuations and particles during the MacWAVE/MIDAS summer 2002 program, Geophys. Res. Lett., 31, L24S08, doi:10.1029/2004GL020169, 2004.

DeLand, M. T., Shettle, E. P., Thomas, G. E., and Olivero, J. J.: A quarter-century of satellite polar mesospheric cloud observations, J. Atmos. Sol. Terr. Phys., 68, 9-29, 2006.

Dushman, S.: Scientific Foundations of Vacuum Technique, Wiley, New York, second edition, 1962.

Fiedler, J., Baumgarten, G., and Lubken, F.-J.: NLC observations during one solar cycle above ALOMAR, J. Atmos. Sol. Terr. Phys., doi:10.1016/j.jastp.2008.11.010, in press, 2009.

Feuerbacher, B. and Fitton, B.: Experimental investigation of photoemission from satellite surface materials, J. Appl. Phys., 43, 1563-1572, 1972.

Friedrich, M., Torkar, K. M., Goldberg, R. A., Mitchell, J. D., Croskey, C. L., and Lehmacher, G.: Comparison of plasma probes in the lower ionosphere, Proc. 13th ESA Symposium on European Rocket and Balloon Programmes and Related Research, ESA SP-397, 381-386, 1997.

Friedrich, M., Torkar, K. M., Singer, W., Strelnikova, I., Rapp, M., and Robertson, S.: Signatures of mesospheric particles in ionospheric data, Ann. Geophys., 27, 823-829, 2009, http://www.ann-geophys.net/27/823/2009/.

Gelinas, L. J., Lynch, K. A., Kelley, M. C., Collins, S., Baker, S., Zhou, Q., and Friedman, J. S.: First observation of meteoric charged dust in the tropical mesosphere, Geophys. Res. Lett., 25, 4047-4050, 1998,

Goertz, C. K.: Dusty plasmas in the solar system, Rev. Geophys., 27(2), 271-292, 1989.

Gordley, L. L., Hervig, M. E., Fish, C., Russell, J. M., Bailey, S., Cook, J., Hansen, S., Shumway, A., Paxton, G., Deaver, L., Marshall, T., Burton, J., Magill, B., Brown, C., Thompson, E., and Kemp, J.: The solar occultation for ice experiment, J. Atmos. Sol. Terr. Phys., doi:10.1016/j.jastp.2008.07.012, in press, 2008.

Gumbel, J.: Aerodynamic influences on atmospheric in situ measurements from sounding rockets, J. Geophys. Res., 106(A6), 10553-10563, 2001.

Gumbel, J. and Megner, L.: Charged meteoric smoke as ice nuclei in the mesosphere: Part 1 - A review of basic concepts, J. Atmos. Sol. Terr. Phys., submitted, 2009.

Gumbel, J. and Witt, G.: Rocket-borne photometry of NLC particle populations, Adv. Space Res., 28(7), 1053-1058, 2001.

Gumbel, J., Stegman, J., Murtagh, D. P., and Witt, G.: Scattering phase functions and particle sizes in noctilucent clouds, Geophys. Res. Lett., 28(8), 1415-1418, 2001.

Gumbel, J., Siskind, D. E., Witt, G., Torkar, K. M., and Friedrich, 
M.: Influences of ice particles on the ion chemistry of the polar summer mesosphere, J. Geophys. Res., 108(D8), 8436, doi:10.1029/2002JD002413, 2003.

Havnes, O. and Næsheim, L. I.: On the secondary charging effects and structure of mesospheric dust particles impacting on rocket probes, Ann. Geophys., 25, 623-637, 2007, http://www.ann-geophys.net/25/623/2007/.

Havnes, O., de Angelis, U., Bingham, R., Goertz, C. K., Morfill, G. E., and Tsytovich, V.: On the role of dust in the summer mesopause, J. Atmos. Sol. Terr. Phys., 52, 637-643, 1990.

Havnes, O., Trøim, J., Blix, T., Mortensen, W., Næsheim, L. I., Thrane, E., and Tønneson, T.: First detection of charged dust particles in the Earth's mesosphere, J. Geophys. Res., 101, 1083910847, 1996.

Hedin, J., Gumbel, J., and Rapp, M.: On the efficiency of rocketborne particle detection in the mesosphere, Atmos. Chem. Phys., 7, 3701-3711, 2007, http://www.atmos-chem-phys.net/7/3701/2007/.

Hervig, M. E., Gordley, L. L., Stevens, M. H., Russell, J. M., Bailey, S. M., and Baumgarten, G.: Interpretation of SOFIE PMC measurements: Cloud identification and derivation of mass density, particle shape, and particle size, J. Atmos. Sol. Terr. Phys., doi:10.1016/j.jastp.2008.07.009, in press, 2009.

Hesstvedt, E.: Nucleation and growth of noctilucent cloud particles, Space Res., 9, 170-174, 1969.

Hoffmann, P., Rapp, M., Serafimovich, A., and Latteck, R.: On the occurrence and formation of multiple layers of polar mesosphere summer echoes, Geophys. Res. Lett., 32, L05812, doi:10.1029/2004GL021409, 2005.

Holzworth, R. H. and Goldberg, R. A.: Electric field measurements in noctilucent clouds, J. Geophys. Res., 109, D16203, doi:10.1029/2003JD004468, 2004.

Hunten, D. M., Turco, R. P., and Toon, O. B.: Smoke and dust particles of meteoric origin in the mesosphere and stratosphere, J. Atmos. Sci., 37, 1342-1357, 1980.

Jacobsen, T. A. and Friedrich, M.: Electron density measurements in the lower D-region, J. Atmos. Terr. Phys., 41, 1195-1200, 1979

Jensen, E. and Thomas, G. E.: Charging of mesospheric particles: implications of electron density and particle coagulation, J. Geophys. Res., 96, 18603-18615, 1991.

Keesee, R. G.: Nucleation and particle formation in the upper atmosphere, J. Geophys. Res., 94, 14683-14692, 1989

Knappmiller, S., Sternovsky, Z., Robertson, S., and Friedrich, M.: A rocket-borne mass analyzer for charged aerosol particles in the mesosphere, Rev. Sci. Instrum., 79, 104502, doi:10.1063/1.2999580, 2008.

Kopp, E. and Herrmann, U.: Ion composition in the lower ionosphere, Ann. Geophys., 2(1), 83-94, 1984.

Kopp, E., Eberhardt, P., Herrmann, U., and Björn, L. G.: Postive ion composition of the high-latitude summer $\mathrm{D}$ region with noctilucent clouds, J. Geophys. Res., 90, 13041-13053, 1985.

Krankowsky, D., Lämmerzahl, P., Götzelmann, A., Friedrich, M., and Torkar, K. M.: Positive ion composition in the lower ionosphere at high latitudes during MAP/WINE, J. Atmos. Terr. Phys.. 49(7/8), 809-818, 1987

Latteck, R., Singer, W., and Bardey, H.: The ALWIN MST radar Technical design and performances, in: Proceedings of the 14th ESA Symposium on European Rocket and Ballon Programmes and Related Research, ESA SP-437, 179-184, 1999.

Lübken, F.-J.: Thermal structure of the arctic summer mesosphere, J. Geophys. Res., 104, 9135-9149, 1999.

Megner, L. and Gumbel, J.: Charged meteoric particles as ice nuclei in the mesosphere: Part 2 - A feasibility study, J. Atmos. Sol. Terr. Phys., submitted, 2009.

Megner, L., Rapp, M., and Gumbel, J.: Distribution of meteoric smoke - sensitivity to microphysical properties and atmospheric conditions, Atmos. Chem. Phys., 6, 4415-4426, 2006, http://www.atmos-chem-phys.net/6/4415/2006/.

Megner, L., Gumbel, J., Rapp, M., and Siskind, D. E.: Reduced meteoric smoke particle density at the summer pole - Implications for mesospheric ice particle nucleation, Adv. Space Res., 41, 41-49, 2008.

Megner, L., Khaplanov, M., Baumgarten, G., Gumbel, J., Stegman, J., Strelnikov, B., and Robertson, S.: Large mesospheric ice particles at exceptionally high altitudes, Ann. Geophys., 27, 943 951, 2009, http://www.ann-geophys.net/27/943/2009/

Natanson, G. L.: On the theory of charging of a microscopic aerosol particles as a result of capture of gas ions, Zh. Tekh. Fiz., 30(5), 573-588, 1960 (English Translation: Sov. Phys. Tech. Phys. 5, $538-551,1960)$

Pedersen, A., Tröim, J., and Kane, J. A.: Rocket measurements showing removal of electrons above the mesopause in summer at high latitude, Planet. Space Sci., 18, 945-947, 1970.

Rapp, M. and Lübken, F.-J.: Modelling of positively charged aerosols in the polar summer mesopause region, Earth Planets Space, 51, 799-807, 1999.

Rapp, M. and Lübken, F.-J.: Modelling of particle charging in the polar summer mesosphere: Part 1 - General results, J. Atmos. Sol. Terr. Phys., 63, 759-770, 2001.

Rapp, M. and Lübken, F.-J.: Polar mesosphere summer echoes (PMSE): Review of observations and current understanding, Atmos. Chem. Phys., 4, 2601-2633, 2004, http://www.atmos-chem-phys.net/4/2601/2004/.

Rapp, M. and Strelnikova, I.: Measurements of meteor smoke particles during the ECOMA-2006 campaign: 1. Particle detection by active photoionization, J. Atmos. Sol. Terr. Phys., doi:10.1016/j.jastp.2008.06.002, in press, 2008.

Rapp, M., Hedin, J., Strelnikova, I., Friedrich, M., Gumbel, J., and Lübken, F.-J.: Observations of positively charged nanoparticles in the nighttime polar mesosphere, Geophys. Res. Lett., 32, L23821, doi:10.1029/2005GL024676, 2005.

Rapp, M., Strelnikova, I., Strelnikov, B., Latteck, R., Baumgarten, G., Li, Q., Megner, L., Gumbel, J., Friedrich, M., Hoppe, U.P., and Robertson, S.: First in situ measurement of the vertical distribution of ice volume in a mesospheric ice cloud during the ECOMA/MASS rocket-campaign, Ann. Geophys., 27, 755-766, 2009, http://www.ann-geophys.net/27/755/2009/.

Robertson, S. and Sternovsky, Z.: Effect of the induced-dipole force on the charging of aerosol particles, Phys. Plasmas, 15, 040702 , doi:10.1063/1.2907162, 2008.

Robertson, S., Smiley, B., Horányi, M., Sternovsky, Z., Gumbel, J., and Stegman, J.: Rocket-borne probes for charged ionospheric aerosol particles, IEEE Trans. Plasma Sci., 32, 716-723, 2004.

Russell III, J. M., Bailey, S. M., Horányi, M., Gordley, L. L., Rusch, D. W., Hervig, M. E., Thomas, G. E., Randall, C. E., Siskind, D. E., Stevens, M. H., Summers, M. E., Taylor, M. I., Englert, C. R., Espy, P. J., McClintock, W. E., and Merkel, A. W.: Aeronomy of 
Ice in the Mesosphere (AIM): Overview and early science results, J. Atmos. Sol. Terr. Phys., in press, 2008.

Schmidt-Ott, A., Schurtenberger, P., and Siegman, H. C.: Enormous yield of photoelectron emission from small particles, Phys. Rev. Lett., 45, 1284-1287, 1980.

Schulte, P. and Arnold, F.: Detection of upper atmospheric negatively charged microclusters by a rocket-borne mass spectrometer, Geophys. Res. Lett., 19(23), 2297-2300, 1992.

Smiley, B., Robertson, S., Horányi, M., Blix, T., Rapp, M., Latteck, R., and Gumbel, J.: Measurement of positively and negatively charged particles inside PMSEs during MIDAS/SOLSTICE 2001, J. Geophys. Res. 108(D8) 8444, doi:10.1029/2002JD002425, 2003.

Sternovsky, Z., Horányi, M., and Robertson, S.: Collision cross sections of small water clusters, Phys. Rev. A, 64, 023203, doi:10.1103/PhysRevA.64.023203, 2001.

Strelnikova, I., Rapp, M., Strelnikov, B., Baumgarten, G., Brattli, A., Svenes, K., Hoppe, U.-P., Friedrich, M., Gumbel, J., and Williams, B. P.: Measurements of meteor smoke particles during the ECOMA-2006 campaign: 2. results, J. Atmos. Sol. Terr. Phys., doi:10.1016/j.jastp.2008.07.011, in press, 2009.

Sugiyama, T.: Ion recombination and growth of ice particles in noctilucent clouds, J. Geophys. Res. 99(A3), 3915-3929, 1994.

Sugiyama, T.: Ionic nucleation of ice particles in noctilucent clouds, in: The Upper Mesosphere and Lower Thermosphere: A Review of Experiment and Theory, Geophysical Monograph, 87, American Geophysical Union, Washington, D.C., 209-214, 1995.

Thomas, L. and Bowman, M. R.: Model studies of the D-region negative-ion composition during day-time and night-time, J. Atmos. Sol. Terr. Phys., 47, 547-556, 1985.

Tsang, T., Srinivasan-Rao, T., and Fischer, J.: Surface-plasmon field-enhanced multiphoton photoelectric emission from metal films, Phys. Rev. B, 43(11), 8870-8878, 1991.

Turco, R. P., Toon, O. B., Whitten, R. C., Keesee, R. G., and Hollenbach, D.: Noctilucent clouds: Simulation studies of their genesis properties and global influences, Planet. Space Sci., 30(11), 1147-1181, 1982.

Ulwick, J. C., Baker, K. D., Kelley, M. C., Balsley, B. B., and Ecklund, W. L.: Comparison of simultaneous MST radar and electron density probe measurements during STATE, J. Geophys. Res., 93(D6), 6989-7000, 1988.
Viehland, L. A. and Mason, E. A.: Transport Properties of gaseous ions over a wide energy range: IV, Atomic Data and Nuclear Data Tables, 60, 37-95, 1995.

von Cossart, G., Fiedler, J., and von Zahn, U.: Size distributions of NLC particles as determined from 3-color observations of NLC by ground-based lidar, Geophys. Res. Lett., 26(11), 1513-1516, 1999.

von Zahn, U., von Cossart, G., Fiedler, J., Fricke, K. H., Nelke, G., Baumgarten, G., Rees, D., Hauchecorne, A., and Adolfsen, K.: The ALOMAR Rayleigh/Mie/Raman lidar: objectives, configuration, and performance, Ann. Geophys., 18, 815-833, 2000, http://www.ann-geophys.net/18/815/2000/.

Vondrak, T., Plane, J. M. C., and Meech, S. R.: Photoemission from sodium on ice: A mechanism for positive and negative charge coexistence in the mesosphere, J. Phys. Chem. B, 110, 38603863, 2006a.

Vondrak, T., Plane, J. M. C., and Meech, S. R.: Influence of submonolayer sodium adsorption on the photoemission of the $\mathrm{Cu}(111)$ /water ice surface, J. Chem. Phys., 125, 224702, doi:10.1063/1.2397675, 2006b.

Vostrikov, A. A., Dubov, D. Yu., and Predtechenskiy, M. R.: Ionization of water clusters by surface collision, Chem. Phys. Lett. 139, 124-128, 1987.

Vostrikov, A. A., Dubov, D. Yu., and Predtechenskii, M. R.: Formation of charged particles in collisions of water clusters with a surface, Sov. Phys. Tech. Phys. 33, 1153-1158, 1988.

Vostrikov, A. A., Zadorozhny, A. M., Dubov, D. Yu., Witt, G., Kazakova, I. V., Bragin, O. A., Kazakov, V. G., Kikhtenko, V. N., Tyutin, A. A.: Ionization of water clusters by collision with surface, Z. Phys. D, 40, 542-545, 1997.

Winkler, P. M., Steiner, G., Vrtala, A., Vehkamäki, H., Noppel, M., Lehtinen, K. E. J., Reischl, G. P., Wagner, P. E., and Kulmala, M.: Heterogeneous nucleation experiments bridging the scale from molecular ion clusters to nanoparticles, Science, 319 , 1374-1377, 2008.

Witt, G.: The nature of noctilucent clouds, Space Res. IX, 157-169, 1969. 